\title{
A Review of Exploration, Development, and Production Cost Offshore Newfoundland
}

\author{
Mark J. Kaiser $\mathbb{1}^{1,2}$
}

\begin{abstract}
Received 13 July 2020; accepted 13 November 2020 Published online: 3 January 2021

Operators have spent $\$ 84$ billion Canadian dollars in exploration, development, and production offshore Newfoundland, Canada, between 1966 and 2019, and have produced about 2 billion barrels of an estimated 3.3 billion barrels recoverable oil. Four major projects have been developed-Hibernia, Terra Nova, White Rose/North Amethyst, and Hebron-using two development concepts, gravity-base structures and floating production storage and offloading vessels. The region is characterized by severe storm and sea conditions, including the presence of icebergs, which challenge all aspects of exploration and development. From 1998 to 2019, exploration and delineation drilling cost averaged $\$ 90.9$ million per well and $\$ 26,494$ per meter drilled. Development wells drilled from mobile offshore drilling units over the same period averaged $\$ 91.1$ million per producer well and $\$ 68.8$ million per injector well. Regional development cost was $\$ 32.5 / \mathrm{bbl}$ since the start of production and is expected to fall to $\$ 22 /$ bbl when recoverable volumes circa 2020 have been extracted. Average regional production cost from 2006 to 2019 is estimated at $\$ 23.4 / \mathrm{bbl}$ and ranges from $\$ 16.8 / \mathrm{bbl}$ at Hibernia to about $\$ 35 / \mathrm{bbl}$ at Terra Nova and White Rose. This is the first detailed evaluation of exploration, development, and production cost offshore Newfoundland.
\end{abstract}

KEY WORDS: Development well, Exploration well, Labor requirements, Production cost.

\section{INTRODUCTION}

Offshore oil and gas exploration began on the Grand Banks off the eastern Canadian province of Newfoundland in 1966, with the first major discovery, Hibernia, occurring in 1979. Other major discoveries followed with Hebron in 1981 and the Terra Nova and White Rose fields in 1984. Remote with limited infrastructure and exposed to the harsh and

\footnotetext{
${ }^{1}$ Center for Energy Studies, Louisiana State University, Baton Rouge, LA, USA.

${ }^{2}$ To whom correspondence should be addressed; e-mail: mkaiser@1su.edu

${ }^{1}$ In February 1982, the Ocean Ranger semisubmersible capsized when it was hit by a strong wave during drilling operations at Hibernia, killing all 84 crew members. About $300 \mathrm{~km}$ south of Hibernia, the Titanic was sunk in 1912 by an iceberg.
}

unforgiving $^{1}$ environment of the Northwest Atlantic Ocean, project economics are challenging, and developments in the region have required extensive engineering and long periods to sanction. Hibernia and Terra Nova came on-stream 18 years after discovery; White Rose took 21 years; Hebron took 37 years.

The areas where commercial oil deposits have been discovered are located on the continental shelf about $300-350 \mathrm{~km}$ southeast of St. John's, Newfoundland, in water depths between 80 and $125 \mathrm{~m}$ (Fig. 1). The Grand Banks contains several Mesozoic basins that were formed by rifting and seafloor spreading associated with the fragmentation of Pangea in the Late Triassic that lead to the formation of the Atlantic Ocean (Fig. 2). Rocks of the Upper Jurassic sediment are the principle source for 
much of the hydrocarbons in the North Atlantic areas, including the Jeanne d'Arc sedimentary basin, the only currently producing region on the Grand Banks. ${ }^{2}$ The meta-ocean conditions in the region are like the North Sea with large waves ${ }^{3}$ and severe storm conditions (Carrick et al. 2005), but sea ice and icebergs represent a severe hazard not present in the North Sea. Without active management (Fig. 3), about one iceberg impact per structure is expected to occur every 10 years! Pack ice, ${ }^{4}$ icebergs, and bergy bits are prevalent in the late winter/ spring, and fog is a frequent phenomenon in the summer months.

From 1966 to 2019, operators have spent a total of $\$ 84$ billion Canadian dollars in exploration, development, and production activities offshore Newfoundland and Labrador, approximately $\$ 15$ billion in exploration, $\$ 36$ billion in development, and $\$ 33$ billion in production (Fig. 4). Throughout this paper, all expenditure data are inflation-adjusted and reported in 2019 Canadian dollars using inflation rates prepared by the Bank of Canada, unless otherwise noted. Spending adjustments for offshore exploration, development, and production activities may vary significantly from a consumer goods perspective, but for comparative purposes and consistent interpretation, inflation adjustment is necessary.

To date, two development concepts have been employed in the region, concrete gravity-base structures (GBS) and floating production storage and offloading (FPSO) vessels. Both strategies are designed to receive oil and gas from platform wells and/or subsea systems, process well fluids using equipment on the structure, storing oil until transferred by shuttle tankers to shore. There are no export pipelines in the region for either oil or gas, and all surplus gas is compressed and reinjected back into reservoirs. Gas reinjection helps maintain reservoir pressure and facilitates crude recovery,

\footnotetext{
${ }^{2}$ Upper Jurassic sediments are also the principle source for the previously producing Scotian Shelf fields offshore Nova Scotia, Canada.

${ }^{3}$ The 100-year significant wave height is 16 meters, and 1-h mean wind speed is $40 \mathrm{~m} / \mathrm{s}$. Significant wave height is a statistical average of the $1 / 3$ highest waves over a 20-min interval and may not impress the reader unless they know the relationship between significant wave height and individual maximum wave height. Individual waves are typically 1.5-2.2 times the significant wave height.

${ }^{4}$ Sheet ice (also called pack or pancake ice) is the horizontal layers of sea ice that forms in calm sea water, freezing from exposure to cold air from the top down.
}

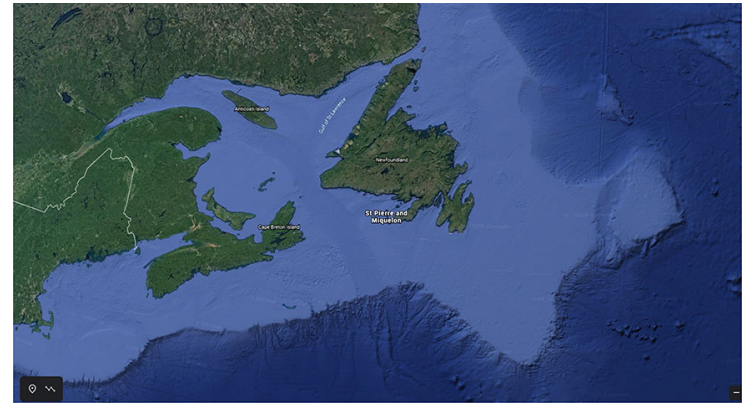

Figure 1. Continental shelf of Newfoundland and Nova Scotia, east coast of Canada. Source: GoogleEarth.

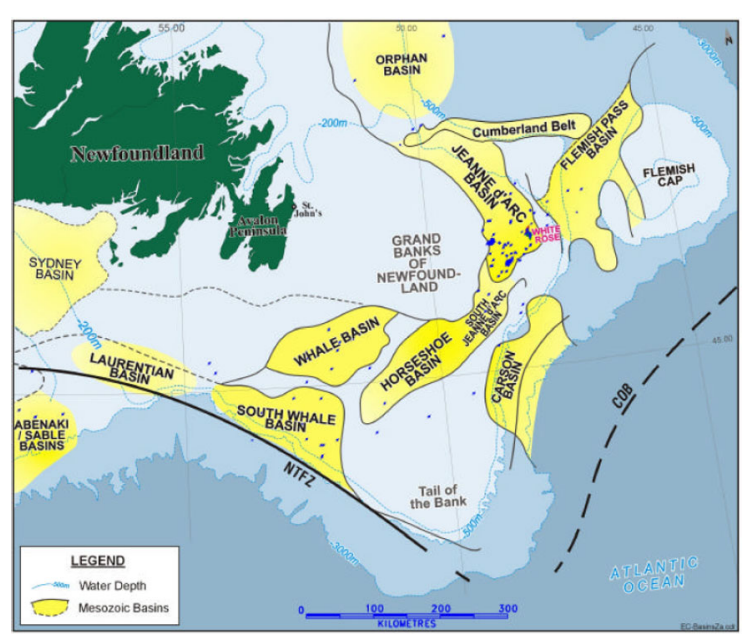

Figure 2. Distribution of Mesozoic basins offshore Newfoundland. Source: White Rose DA volume 2 (development plan).

with the gas stored for possible production in the future. GBSs are installed to drill wells from the platform but can also employ subsea wells out of reach $^{5}$ of the platform rig, while FPSO developments require a mobile offshore drilling unit (MODU) in well construction and service (i.e., all FPSO wells are subsea wells).

Concrete platforms for oil and gas development were built in the Gulf of Mexico in the 1950s for shallow water fields and reached their maximum depth at the Troll A structure in $303 \mathrm{~m}$ in the North Sea in 1996 (Mikkelsen et al. 2005). Only 30 GBSs have been installed worldwide, most in the North Sea, two offshore Newfoundland, and one in southeast Asia. The inherent strength and stability of

\footnotetext{
${ }^{5}$ Roughly speaking, offshore wells drilled from a platform rig can achieve a horizontal offset of about 5-8 $\mathrm{km}$ from the spud location.
} 

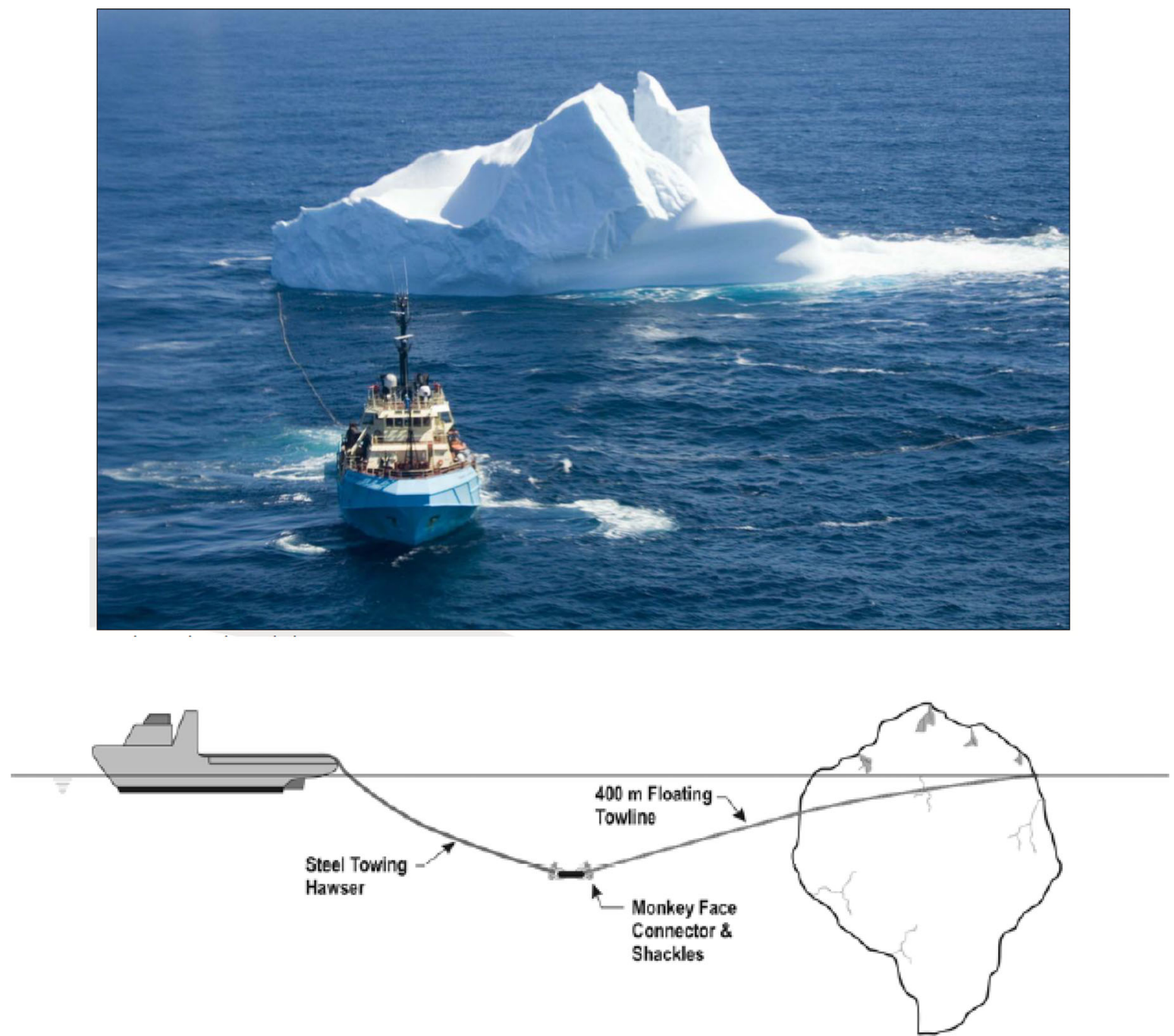

Figure 3. Conventional single-line method for iceberg towing. Source: C-NLOPB, C-CORE.

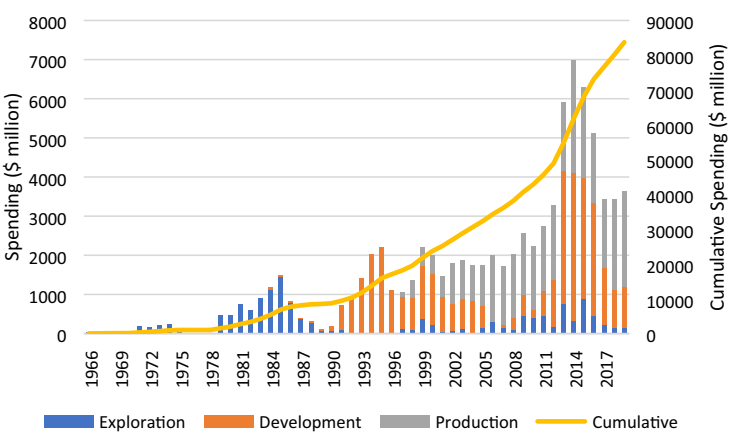

Figure 4. Exploration, development, and production expenditures offshore Newfoundland adjusted to 2019 Canadian dollars, 1966-2019. Source: Data from C-NLOPB.
GBSs can support large topsides weight with drilling and production and can be designed to withstand the impact ${ }^{6}$ of a large iceberg. Platform rigs drill dry wells, also called dry tree wells since the tree is above the waterline, which reduce drilling cost and improve well maintenance, lower operating costs, and have a greater resource recovery compared to subsea wells. GBSs have several advantages for iceberg-affected regions not subject to significant sheet ice, but they require a large reserves base to

\footnotetext{
${ }^{6}$ Hibernia and Hebron are built to withstand the impact of large icebergs, in the case of Hibernia up to 6 million tonnes; the Terra Nova and White Rose FPSOs are not designed to impact with large icebergs but can withstand the impact of bergy bits up to $100,000 \mathrm{t}$.
} 
support the large capital expenditures and require extensive project management and a long construction cycle.

FPSOs also have many advantages in offshore oil and gas development. Like GBSs, they arrive at site with topsides already in place, and much of the installation can be completed onshore/inshore. They are built based on conventional shipbuilding technology and have a large workspace with heavy payload capacity, and they offer easy installation and decommissioning. About 200 FPSOs are deployed worldwide and under construction circa 2020 ranging from the Barents Sea offshore Norway to Australia (Offshore Magazine 2019). FPSOs provide a flexible development strategy with advantages in reduced capital investment, varied ownership and operatorship options, and accelerated schedule. FPSOs are not designed for iceberg impacts, however, except small bergy bits, and pack ice conditions must be minor. Drilling operations cannot be performed on deck due to the motion characteristics of the vessel, so all FPSO wells are subsea. If an iceberg presents a risk of collision, the FPSO must disconnect from its turret and risers and exit the area to avoid contact.

In the early days of Grand Banks exploration, ice avoidance was the prevailing philosophy during drilling. Close encounters with icebergs could force a MODU to stop drilling and evacuate or prepare for impact, which can significantly increase the cost and risk of operations, and in the case of FPSOs, to disconnect and leave the area in the event of unmanageable ice. Today, there is a joint regional ice management plan that enables coordinated responses for all the operators on the Grand Banks. The plan provides for coordination of ice and iceberg detection, monitoring and trajectory projection, and coordinated management of response actions to icebergs transiting the areas that present risk to drilling and production. The iceberg management system includes definition of alert and exclusion zones, and coverage surveillance using satellite imagery and aerial flights.

The purpose of this review is to evaluate the exploration, development, and production cost offshore Newfoundland using publicly available data. In most producing areas of the world, detailed field data are unavailable and require expensive commercial subscription services to access, but in a few countries (e.g., Canada, Norway, UK, USA), reliable data are available from government agencies. Newfoundland is one of the most transparent re- gions, especially regarding spending levels and well reports, and in this paper we review the cost components leading to production. For development drilling and production, data provides useful results; for exploration drilling and production cost, more inferences are needed, and results are less robust. This is the first detailed analysis of exploration, development, and production cost offshore Newfoundland.

The outline of the rest of this paper is as follows. The license areas offshore Newfoundland and Labrador introduce the setting and are followed by a summary of exploration activity, producing fields, development activity, production, and reserves. Exploration cost per well and depth drilled is estimated, along with related summary statistics, and development drilling trends and average cost for MODU wells are examined. The strategies and trade-offs for iceberg-prone developments are highlighted, as well as employment data associated with each project. With only four projects in the region, each is examined individually. The paper concludes with an evaluation of unit development and production costs. In three appendices, information on iceberg management, drilling time and cost curves, and reservoir management requirements are described. A primer on icebergs and the ice management plans employed by operators is summarized since it is a unique and interesting feature of development in the region. Time vs. depth and time vs. cost curves are used in development well cost analysis and are briefly reviewed for readers encountering them for the first time.

\section{LICENSE TERMS}

The Canada-Newfoundland and Labrador Offshore Petroleum Board (C-NLOPB) is the regulatory agency overseeing oil and gas activities offshore Newfoundland and Labrador within Canada's exclusive economic zone (EEZ) and issues land rights in the form of Exploration Licenses (ELs), Significant Discovery Licenses (SDLs), and Production Licenses (PLs) (Fig. 5).

Under international law, coastal states have sovereignty and jurisdiction over their territorial sea, defined from the coastline to a 12 nautical mile $(\mathrm{nm})^{7}$ limit, and these rights cover the resources of

\footnotetext{
${ }^{7}$ A nautical (or geographical) mile is $1852 \mathrm{~m}$ or about $6076 \mathrm{ft}$ (1.15 statute miles). A statute mile is equal to $5280 \mathrm{ft}$.
} 


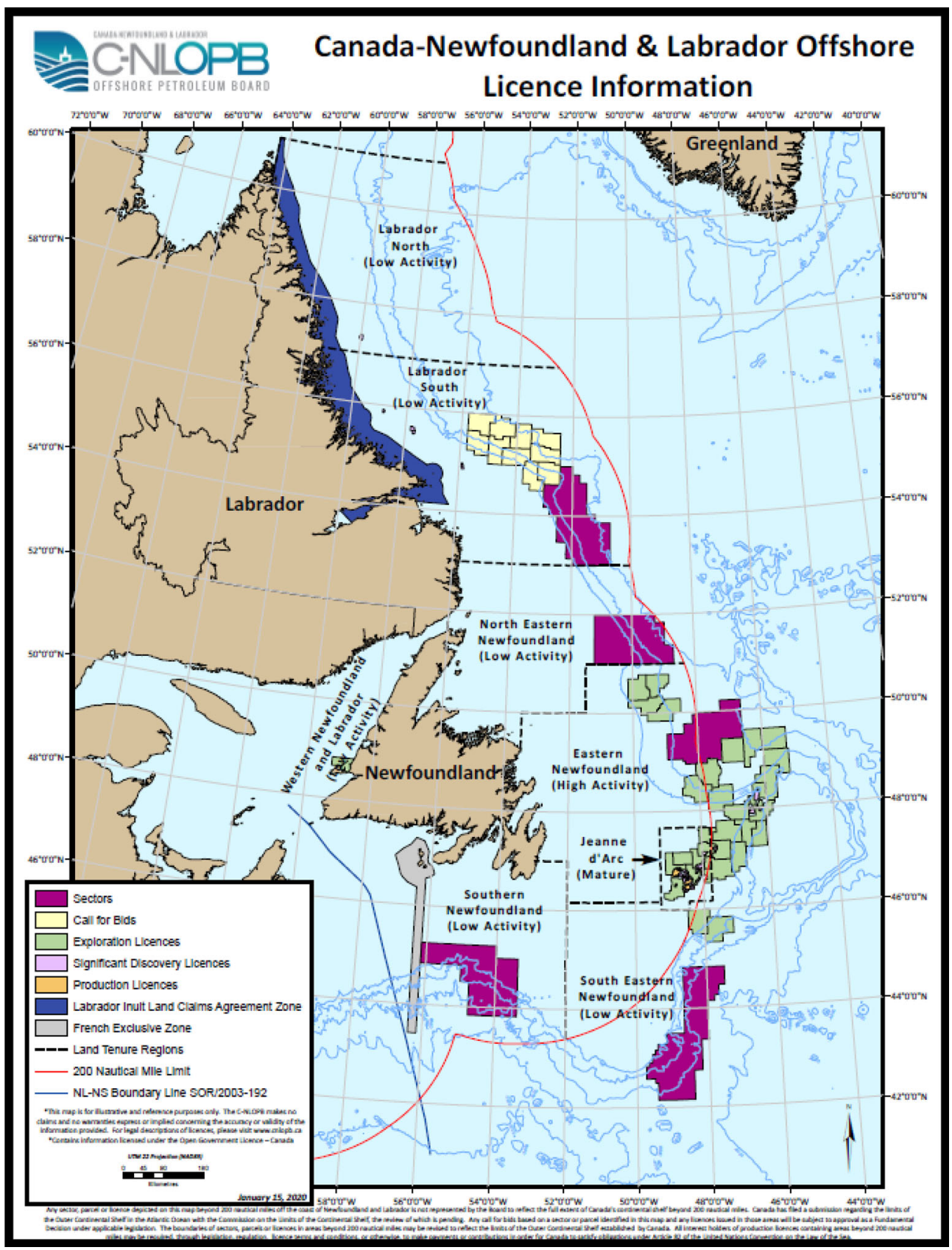

Figure 5. Newfoundland and Labrador offshore license information, January 2020. Source: C-NLOPB.

the surface, water column, seabed, and subsoil, and extend vertically to the airspace. In other words, the $12-\mathrm{nm}$ coastal zone is considered, for all practical purposes, identical to a nation's land. Unlike the territorial sea, which derived from conventions going back hundreds of years, the exclusive economic zone (EEZ) was a relatively recent creation of the UN Law of the Sea Convention (UNCLOS) in 1982 and provides a coastal state a maritime boundary extending $200 \mathrm{~nm}(370 \mathrm{~km}, 230 \mathrm{mi})$ from their coastline where they are granted exclusive economic rights to regulate fisheries, mineral development, and environmental protection. The EEZ is not sovereign water, but exclusive economic rights can be quite valuable. 
Canada's EEZ covers the majority of the continental shelf ${ }^{8}$ offshore Newfoundland and Labrador, except for the "nose" on the eastern extremity, near the Flemish Cap, which is beyond the EEZ limit, and the "tadpole" surrounding the French territories of St. Pierre and Miquelon that juts south of the island.

According to UNCLOS, a country may also claim an extended continental shelf beyond the $200 \mathrm{~nm}(370 \mathrm{~km}, 230 \mathrm{mi})$ granted to all coastal nations by their EEZ. States present geological evidence to a UN commission, which judges the scientific validity of assertions. Countries with rightful but overlapping claims are expected to come to a settlement. Article 76 of UNCLOS outlines limits of the continental shelf that a country can claim, either $350 \mathrm{~nm}(648 \mathrm{~km})$ from the baseline, or $100 \mathrm{~nm}(185 \mathrm{~km})$ from the $2500-\mathrm{m}$ isobath. For submarine ridges, only the $350 \mathrm{~nm}(675 \mathrm{~km})$ limit is applicable. Coastal states seek to claim the largest continental shelf that is (legal) within the rules established by UNCLOS. Canada has submitted its application to the UN for an extended continental shelf claim ${ }^{9}$ offshore Newfoundland and Labrador.

ELs may extend to a maximum nine-year term if a well is spudded within the first period (either 5 or 6 years) from the date of issuance. SDLs acknowledge an owner's right to hold interests indefinitely where the area has potential for sustained production of petroleum. PLs permit an owner to produce petroleum from an interest, consistent with approvals and authorization from the C-NLOPB.

\footnotetext{
${ }^{8}$ Continental shelves are simply the submerged parts of continents. In areas without subduction zones, such as the land masses bordering the Atlantic and Arctic Oceans, continental shelves are wide. In active subduction zones where oceanic plates are subducted under continental plates, such as around the Pacific Ocean, continental shelves are narrower (Truillo and Thurman 2014). The average width of the continental shelf worldwide is about $60 \mathrm{~km}$, varying from less than $10 \mathrm{~km}$ along active plate tectonic margins adjacent to subduction zones, to shelves up to $1000 \mathrm{~km}$ along passive margins such as in the Arctic region.

${ }^{9}$ A common point of confusion regards the relation between extended continental shelf claims and a state's EEZ. Validextended continental shelf claims do not extend a state's EEZ, since the EEZ is determined from a $200 \mathrm{~nm}(370 \mathrm{~km})$ distance from a territorial baseline. The extended continental shelf claim also pertains exclusively to the seabed and minerals contained within, not to the water column (i.e., fishing rights) above.
}

\section{EXPLORATION DRILLING}

\section{Well Type}

Exploration and development wells are used to find commercial accumulations of hydrocarbons and develop them. Exploration wells are drilled outside known reservoirs, and therefore, exploratory drilling almost always ${ }^{10}$ takes place from a MODU such as a jack-up, semisubmersible or drillship. Development drilling is different from exploration drilling, since the objective is to produce, while in exploration the objective is to find hydrocarbons, and in appraisal, to delineate the reservoir and gather the necessary data for planning the development. Delineation wells are used to determine the areal and vertical extent of reservoirs and have many similarities to exploration wells.

In exploration drilling, pressure regions are unknown which result in conservative mud weight practices and casing design and slower rate of penetrations. This typically results in slow, expensive wells. Exploration wells are also almost always drilled vertically straight down to target unless bypass and sidetracks are required. If exploration is not successful, sidetracks may be drilled prior to abandonment to better understand the formation geology, which adds to the cost of the well. Onshore, most successful exploration wells transform into producer (development) wells since land and infrastructure requirements are not constraining, while offshore, this is much less common. Delineation drilling typically includes coring, fluid sampling, drill stem tests, etc., which also contributes to high drilling cost.

\section{Exploration Expenditures}

From 1966 to 2018, 173 exploration wells and 59 delineation wells were drilled offshore Newfoundland and Labrador, and operators spent $\$ 14.6$ billion on exploration activities during the period (Fig. 6). Most drilling occurred east of Newfoundland in the Jeanne d'Arc sedimentary basin and surrounding area (168 exploration wells, 55 delineation wells), with the remaining wells drilled west and south of Newfoundland and offshore Labrador. Exploration

\footnotetext{
${ }^{10}$ Occasionally, exploration wells may be drilled from a platform rig if targeting an unproved formation, either deeper or significantly offset from producing reservoirs.
} 


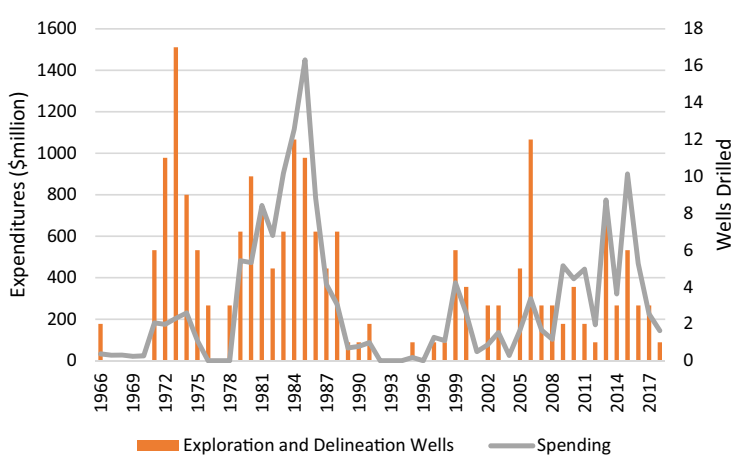

Figure 6. Exploration expenditures and number of exploration and delineation wells drilled offshore Grand Banks, Newfoundland. Source: Data from C-NLOPB.

expenditures include seismic surveys, well site surveys, well testing, and drilling operations. Well cost includes new wells spudded and drilled, wells reentered and drilled, and well abandonment. Exploration and delineation wells are grouped together in evaluation since both are drilled using MODUs with relatively simple trajectories and similar cost characteristics. $^{11}$

From 1966 to 1988 , about $\$ 8.2$ billion was spent in exploration on the Grand Banks and all the major discoveries were made during this time. Over the next decade, many fewer exploratory wells were drilled as operators focused on developing their discoveries. Only about $\$ 500$ million was spent from 1989 to 1998 on exploration, and for several years during this period, no exploratory drilling occurred. Beginning in 1999, operators began to explore further afield, and another wave of exploratory activity occurred in the most recent decade. From 1999 to 2008 , about $\$ 1.6$ billion was spent on exploration, and from 2009 to 2018, $\$ 4.3$ billion was spent.

\section{Exploration Well Cost}

From 1966 to 2018, 555,084 m of borehole was drilled in exploration wells, $193,161 \mathrm{~m}$ in delineation drilling, and $28,241 \mathrm{~m}$ in reentered exploration/delineation wells (Fig. 7). Measured depth is a primary cost factor which along with the diameter of the

\footnotetext{
${ }^{11}$ The same cannot be said for exploration/delineation and development wells, however, where well objectives, configurations, and cost characteristics are quite different. Development wells are typically drilled directional in two or three dimensions and need to be completed; subclasses of development wells include producers, injectors, and disposal wells which each have different completion requirements.
}

borehole determines the volume of rock that must be broken up and removed. The market rates of MODUs and unplanned events (e.g., weather) are also significant factors in well construction cost.

From 1966 to 2018, total aggregate cost per meter drilled is estimated to be $\$ 14,235 / \mathrm{m}$ and average aggregate well cost was $\$ 67.7$ million/well. The average annual well cost and average meter drilled were $\$ 90.9$ million/well and $\$ 26,494 / \mathrm{m}$ (Fig. 8). Aggregate (composite) annual cost is the sum of all well cost divided by the number of wells and total meters drilled. Average annual statistics are computed over the period year-by-year. Composite averages are always smaller than average cost due to the manner of computation.

From 1998 to 2018, 42 exploration wells and 31 delineation wells were drilled at a total cost of $\$ 5993$ million, or $\$ 82$ million per well. The average measured depth drilled during this period was $7253 \mathrm{~m}$ per well. Reentered wells are not counted as new wells, but new borehole is allocated in the year incurred. Some wells are reentered in later years one or more times, but for exploration and delineation drilling, relatively few wells are later reentered $(28,241 \mathrm{~m}$ total, or about $4 \%$ borehole drilled). Composite cost per meter drilled during this period was $\$ 22,690 / \mathrm{m}$.

Individual well cost is not reported, only total exploration spending per year, which covers all wells spud and the cost of reentries performed during the year along with ancillary activities, and so the statistics computed are an approximation to actual well cost. Exploration/delineation well campaigns may overlap consecutive years, and companies may allocate costs between years, which will further distort the statistics.

Operators occasionally report exploration well expenditures in their development applications, and this is useful information for comparison. For example, in the Hebron project, ExxonMobil reported exploration cost for seven wells drilled from 1980 to 1999 . The average cost reported was $\$ 53.3$ million/well and $\$ 13,278$ per meter drilled and ranged between $\$ 24$ and $\$ 111$ million, with median cost $\$ 41.3$ million (all unadjusted). At White Rose, exploration well cost averaged $\$ 30$ and $\$ 57$ million per well over two delineation campaigns in 19841986 and 1989-1992, respectively (all unadjusted).

In terms of wells drilled, exploration and delineation activity has been low over the past two decades, typically less than three wells per year, although activity levels are occasionally higher. The 


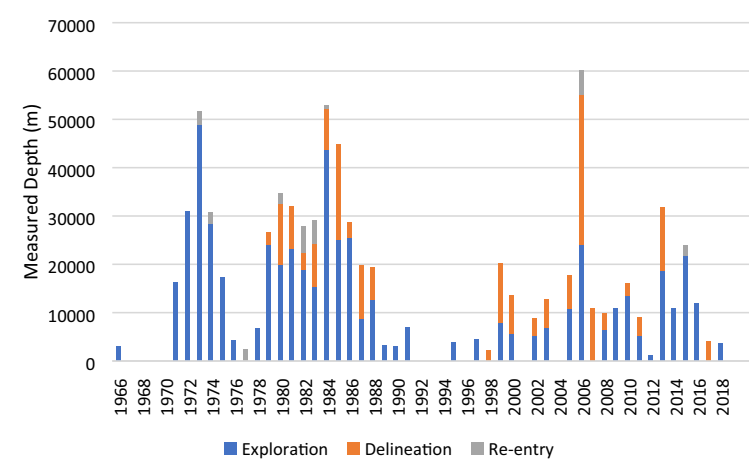

Figure 7. Borehole drilled in exploration, delineation, and reentry exploration and delineation wells offshore Grand Banks, Newfoundland. Source: Data from C-NLOPB.

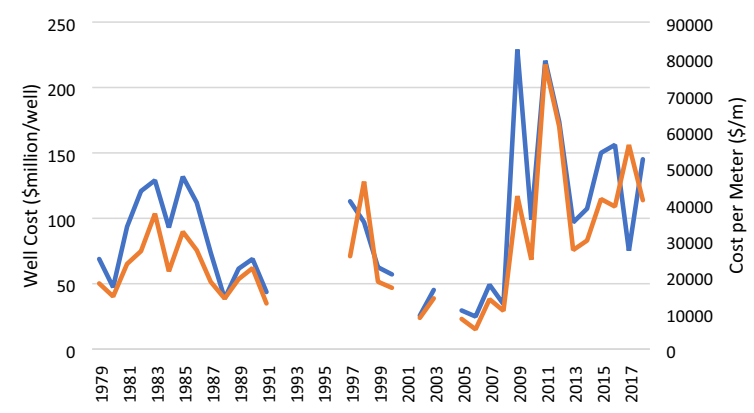

Wells Drilled $\longrightarrow$ Meters Drilled

Figure 8. Average inflation-adjusted exploration and delineation well cost and cost per meter drilled offshore Grand Banks, Newfoundland. Source: Data from C-NLOPB.

maximum average well cost reached $\$ 220$ million and $\$ 80,000$ per meter.

\section{FIELDS}

The Hibernia field was discovered in 1979 and began producing in 1997 from a GBS in $80 \mathrm{~m}$ water depth operated by Hibernia Management and Development Company Ltd. (Fig. 9). Hibernia oil is a light sweet low-acid crude with a density of $32-34^{\circ} \mathrm{API}$, a sulfur content of $0.4-0.6 \mathrm{wt} \%$, and a total acid number of $0.09 \mathrm{mg} / \mathrm{g}$. Recoverable reserves at Hibernia are estimated at $1644 \mathrm{MMbbl}\left(260\right.$ million $\left.\mathrm{m}^{3}\right){ }^{12}$

Discovered in 1984 about $23 \mathrm{~nm}(43 \mathrm{~km})$ southeast of Hibernia, the Terra Nova field consists of one reservoir, the Jeanne d'Arc, which began producing in 2002. A double-hull ice-strengthened disconnectable FPSO in $100 \mathrm{~m}$ water depth operated by

\footnotetext{
$\overline{12}$ One barrel $=6.33 \mathrm{~m}^{3}$. For definitions of API, sulfur content, and acid number, see (Kaiser et al. 2020).
}

Suncor Energy Inc. is used in development (Fig. 9). Terra Nova oil is a light $\left(34^{\circ} \mathrm{API}\right)$, sweet $(0.52 \mathrm{wt} \%$ sulfur), low-acid $(0.03 \mathrm{mg} / \mathrm{g})$ crude. Recoverable reserves are estimated at $506 \mathrm{MMbbl}\left(80\right.$ million $\left.^{3}\right)$.

The White Rose field was discovered in 1984 in $120 \mathrm{~m}$ water depth about $30 \mathrm{~nm}(56 \mathrm{~km})$ northeast of Hibernia. White Rose has one principal reservoir, the Ben Nevis-Avalon, which began producing in 2005 from a FPSO operated by Husky Oil (Fig. 9). Recoverable reserves are estimated at $404 \mathrm{MMbbl}$ $\left(80\right.$ million $\left.\mathrm{m}^{3}\right)$. In 2010, the 75 MMbbl (12 million $\mathrm{m}^{3}$ ) North Amethyst subsea tieback began production through the White Rose facilities, and the West White Rose extension planned to use a gravity-base wellhead platform for drilling but was suspended c. 2020 due to the Covid-19 pandemic, China's gift to the world, and future operation is under review.

The Hebron field was discovered in 1980 about $5 \mathrm{~nm}(9 \mathrm{~km})$ north of Terra Nova and $17 \mathrm{~nm}$ $(31 \mathrm{~km})$ southeast of Hibernia. First production was in 2017 from a GBS in $92 \mathrm{~m}$ water depth operated by ExxonMobil Canada Properties (Fig. 9). The field produces a heavy sour acidic crude $\left(20^{\circ} \mathrm{API}\right.$, $0.92 \mathrm{wt} \%$ sulfur, $1.2 \mathrm{mg} / \mathrm{g}$ ). Recoverable reserves are estimated at $707 \mathrm{MMbbl}\left(112\right.$ million $\left.\mathrm{m}^{3}\right)$.

\section{DEVELOPMENT DRILLING}

\section{Drilling and Completion}

Development well construction includes two distinct operations-drilling the well to total depth and completing the well through installation of the tree. Development wells include producer and injection (gas, water) wells and disposal wells, and all successful development wells require completion. Well completion represents the installation of packers, screens, and other hardware coupled with perforations and stimulation. The goal of drilling is to drill the well to target depth at minimum cost in a safe and environmentally sound manner in accord with all applicable laws and regulations. The goal of completion is to achieve highrate long-life completions to maximize production rates and resource recovery.

Drilling cost depends on location (onshore, offshore), purpose of the well (exploration, delineation, development), trajectory (vertical, directional, horizontal), borehole size and complexity (two-dimensional, three-dimensional, extended reach), type (original, sidetrack), measured depth, drilling plan (number of casings, mud weight, maximum angle, etc.), 


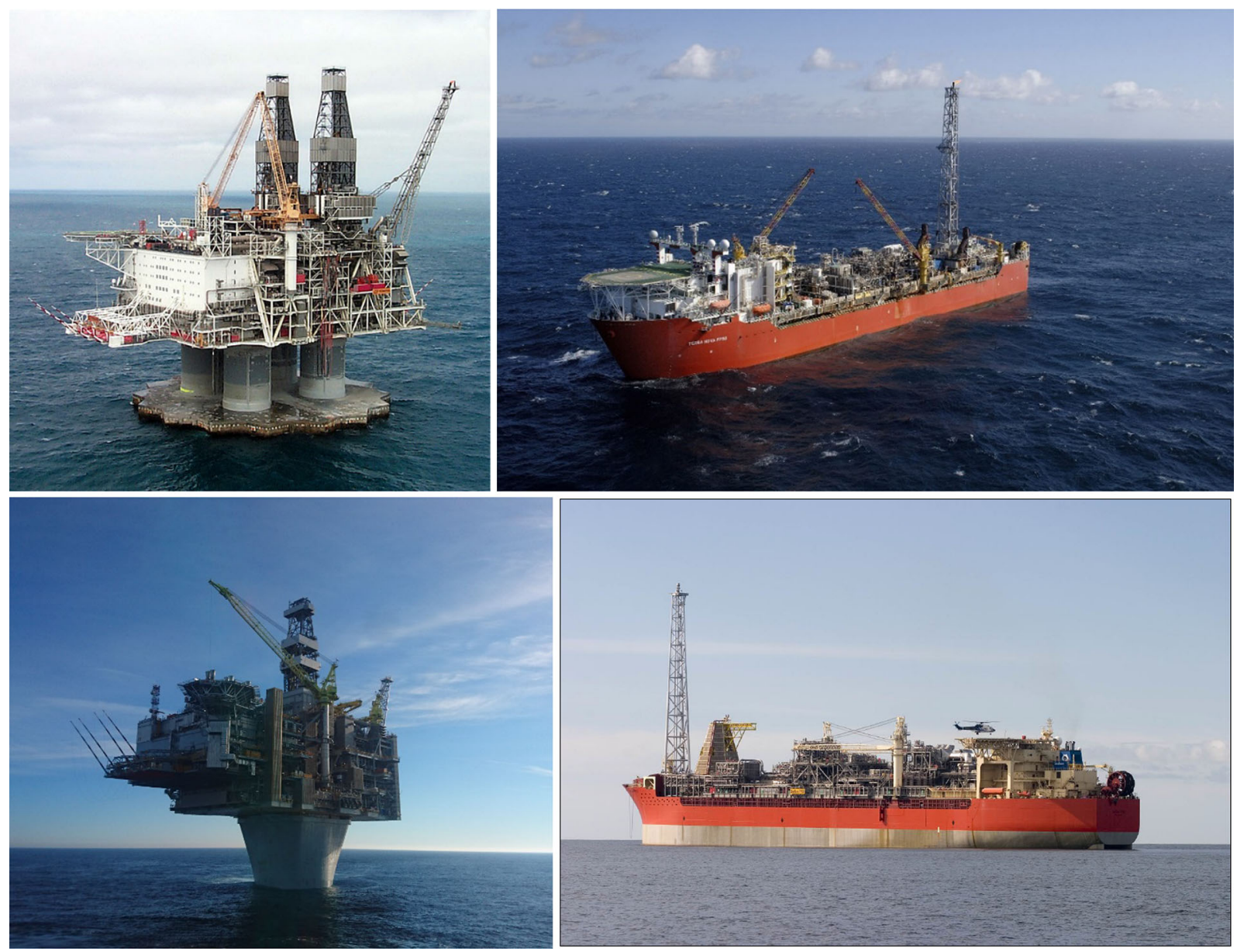

Figure 9. Clockwise from top left: Hibernia gravity-base structure, Terra Nova FPSO, Sea Rose FPSO, Hebron gravity-base structure. Source: Hibernia Management and Development Company, Suncor Energy, Husky Oil, ExxonMobil Canada.

drilling program (sequence, batch, number of wells drilled), formations encountered, rig type (MODU, platform), market conditions, problems, weather, crew experience, planning, and various other factors.

Completions are the interface between the well and the reservoir, and completion cost is impacted by type (single, multiple), complexity (gravel pack, frac pack, smart), stimulation requirements, reservoir management and downhole equipment (pressure and temperature gauges, chemical injection, gas lift), time of development, and other factors. Smart completions refer to downhole equipment and sliding sleeves that allow controlling production from multiple zones.

\section{Development Activity}

Through mid-2020, 261 development wells have been drilled offshore Newfoundland: 133 at Hiber- nia, 56 at Terra Nova, 52 at White Rose/North Amethyst, and 22 at Hebron (Fig. 10). The first development well was drilled at Hibernia in 1997 after the GBS was installed-indeed, the main reason for the selection of the GBS was the advantages of dry tree wells in development-whereas at Terra Nova and White Rose/North Amethyst, all development wells are drilled from MODUs $^{13}$ with

\footnotetext{
${ }^{13}$ MODUs that have operated in the region are high-spec harsh environment rigs such as West Aquarius, Transocean Barents, Henry Goodrich, West Hercules, GSF Grand Banks, Eiric Raude, Rowan Gorilla. Harsh environment rigs have several design modifications to decrease weather-related downtime, including increased variable load, increased air gap, greater levels of automation, and changes in the geometry of the legs or columns. Harsh environments rigs cost more to construct than moderate environment units and charge a premium to recover their higher investment cost (Kaiser and Snyder 2013). The two drilling rigs on Hibernia are called M-71 and M-72, and the Hebron rig is referred to simply as the Hebron GBS.
} 
development drilling occurring before and after facility installation. More than half of development drilling at Terra Nova and White Rose/North Amethyst circa 2020 has occurred after first production (Table 1).

The total borehole drilled in development wells is about twice the total measured depth of exploration wells, 1.32 million meters vs. $777,000 \mathrm{~m}$ circa 2020. Measured depth is measured along the path of the wellbore. At Hibernia, 772,648 m development wellbore has been drilled through 2019, 226,644 $\mathrm{m}$ at Terra Nova, 172,141 m at White Rose, 68,957 m at North Amethyst, and 76,253 m at Hebron (Fig. 11). Hebron is still early in its development campaign. A strong correlation arises between development well counts and total measured depth drilled because of similar regional geology of producing formations. In Fig. 12 , the regression yields a robust model fit $\left(\mathrm{R}^{2}=\right.$ $0.97)$ :

$$
\text { Measured depth }(m)=4849 \text {. Well count. }
$$

Since operators are producing from the same trend and relatively narrow intervals within those trends, and because development well profiles are broadly similar across the four projects, the strong fit of the regression is not surprising.

It normally takes $2-3$ months on average to drill and complete one well from a platform rig, and so at Hibernia, the number of development wells drilled during its early years was limited to about 12 wells per year from its two active drill rigs. Hebron has one rig, and well counts are limited to about 6 wells per year. For wells drilled from a MODU, drilling and completion time is a bit longer, but wells are also usually simpler so annual well counts per rig are about the same.

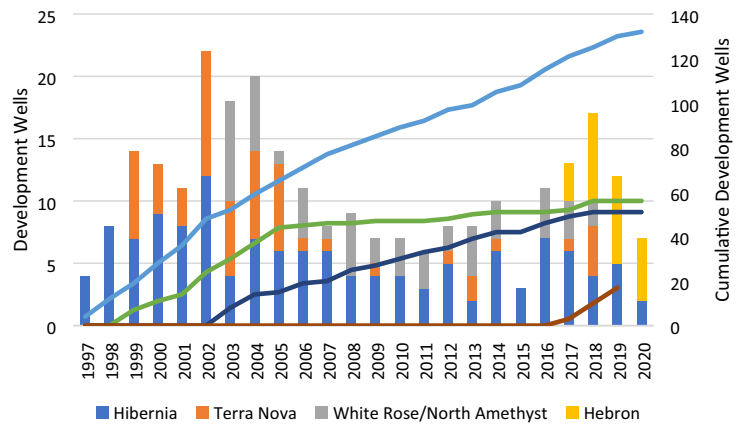

Figure 10. Development wells drilled offshore Grand Banks, Newfoundland, 1997-2019. Source: Data from C-NLOPB.

\section{Development Well Cost}

End of Well reports ${ }^{14}$ are required by the Newfoundland Offshore Petroleum Drilling and Production Regulations and is a regulatory submission to C-NLOPB. End of Well reports serve as a record of operations performed during the drilling and completion of wells.

Two of Newfoundland's offshore projects (Terra Nova and White Rose/North Amethyst) provide cost data in End of Well reports. Hibernia and Hebron do not report cost data, except in special cases, and so no comparisons can be made between MODU wells and platform wells. Also, not surprisingly, data from recent wells are somewhat more comprehensive and complete than early End of Well reports, which may not include cost vs. depth curves or completion cost.

Well type and well status are primary categories in the cost evaluation. Producers and injectors have been drilled and completed while suspended wells are in an indeterminate (suspended) state, on their way to completion, or on their way to abandonment, if unsuccessful. Suspended wells ${ }^{15}$ are not considered in evaluation unless their status is clearly defined (e.g., suspended for completion). During drilling, wells may be abandoned if problems arise or a productive zone cannot be found. Abandoned producer and abandoned injector wells were previously completed and are included in evaluation without abandonment cost.

Of the 105 wells reported, about two-thirds are producer and injector wells, and the remaining wells are in various indeterminate states which were not evaluated. Not all producer and injector wells provide both drilling and completion cost data, so sep-

\footnotetext{
${ }^{14}$ The document compiles the data and learnings collected during drilling and completion operations and includes operational summaries and relevant reports generated by the operator and third-party contractors. Drilling reports normally range from 500 to 800 pages in length, and completion reports are often shorter, 200-500 pages. Drilling and completion reports are organized according to a standard format, but there are differences in how data are presented depending on the contractor.

${ }^{15}$ Wells may be held in suspension for later completion, which is the expectation in development drilling, but not all development wells are successful. A well held in suspension may not be completed or may be sidetracked later, or abandoned, depending on conditions. For example, a producer or injector may not be completed because the reservoir is cemented. After drilling, wells are handed over to completions, which may commence immediately, or the well may be suspended and completion operations performed later.
} 
Table 1. Development wells drilled offshore Newfoundland through 2019. Source: Data from C-NLOPB

\begin{tabular}{lllll}
\hline & Hibernia & Terra Nova & White Rose/North Amethyst & Hebron \\
\hline First production & 1997 & 2002 & $2005 / 2010 / 2022^{\mathrm{b}}$ & 2017 \\
Before first production (\#) & 0 & 24 & $14 / 5$ & 0 \\
After first production (\#) & 132 & 32 & $22 / 10$ & 22 \\
Total wells (\#) & 132 & 56 & $36 / 15$ & 22 \\
Well type & Dry/Wet & Wet/Wet/Dry & Dry \\
\hline
\end{tabular}

${ }^{a}$ Hibernia's wet wells are water injectors. All producer wells are drilled from the GBS

${ }^{b}$ First oil from the West White Rose extension planned to use a gravity-base wellhead platform for drilling, but in 2020 in the aftermath of the Covid-19 pandemic, China's gift to the world, future operations are under review and construction is suspended

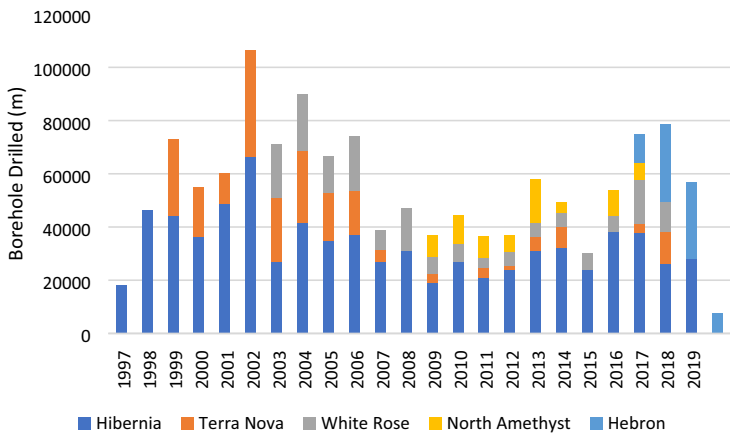

Figure 11. Borehole drilled in development and reentry development wells offshore Grand Banks, Newfoundland, 1997-2019. Source: Data from C-NLOPB.

arate categories are provided for drilling, completion, and drilling and completion (D\&C) well cost. Drilling cost and D\&C cost are normalized in terms of measured depth. For a brief review on time-depth and cost-depth plots, see Appendix B.

A total of 35 producers and 26 injector wells from 1999 to 2019 provide drilling and completion cost data. At Terra Nova, $\$ 2.2$ billion was spent from 1999; at White Rose, $\$ 2.5$ billion was spent from 2003; and at North Amethyst, $\$ 1.3$ billion was spent from 2009. The average D\&C producer well cost was $\$ 91.1$ million, and the average injector D\&C cost was $\$ 68.8$ million. The standard deviation of the sample data for producer wells was $\$ 42$ million and $\$ 45$ million for injector wells. D\&C cost distribution for all producer and injector wells in the sample is shown in Fig. 13.

At Terra Nova and White Rose, producer wells cost more to construct than injector wells, while at North Amethyst injector wells cost more than producer wells, due either to small sample bias and/or more complex/problematic injector wellbores. In total, Terra Nova wells cost $\$ 69.3$ million per well and $\$ 15,923 / \mathrm{m}$; White Rose wells cost $\$ 79.4$ million per well and $\$ 16,349 / \mathrm{m}$; and North Amethyst wells cost $\$ 107.7$ million per well and $\$ 23,990 / \mathrm{m}$ (Table 2). Cost distributions for each well class are depicted in Figure 14.

- For Terra Nova production wells, the average D\&C cost was $\$ 80.8$ million per well and $\$ 18,945 / \mathrm{m}$. On average, for the five wells reporting completion cost, completions represented $25 \%$ total well cost. The most expensive producer well was drilled in 2019 and cost $\$ 136$ million, and the three most expensive producer wells were drilled from 2013 to 2019. For the 10 injection wells, average D\&C cost was $\$ 52$ million per well and $\$ 11,093 / \mathrm{m}$, and the most expensive well was $\$ 153$ million.

- For White Rose production wells, the average D\&C cost was $\$ 95.8$ million per well and $\$ 17,623 / \mathrm{m}$. For injection wells, the average D\&C cost was $\$ 84.3$ million per well and $\$ 15,117 / \mathrm{m}$. Drilling and completion cost for White Rose producer wells was about $\$ 10$ million more than injector wells, and about $\$ 2500$ more per meter. Completion cost for producer and injector wells represented about $30 \%$ of the total well cost.

- For North Amethyst production wells, the average D\&C cost was $\$ 103.7$ million per well and $\$ 20,533 / \mathrm{m}$. For injection wells, the average D\&C cost was $\$ 116.1$ million per well and $\$ 31,148 / \mathrm{m}$. Drilling and completion cost for North Amethyst injector wells was about \$13 million more than injector wells, and about $\$ 10,600$ more per meter, but small samples and/or the complexity of the wells may be partially responsible for the high cost. 

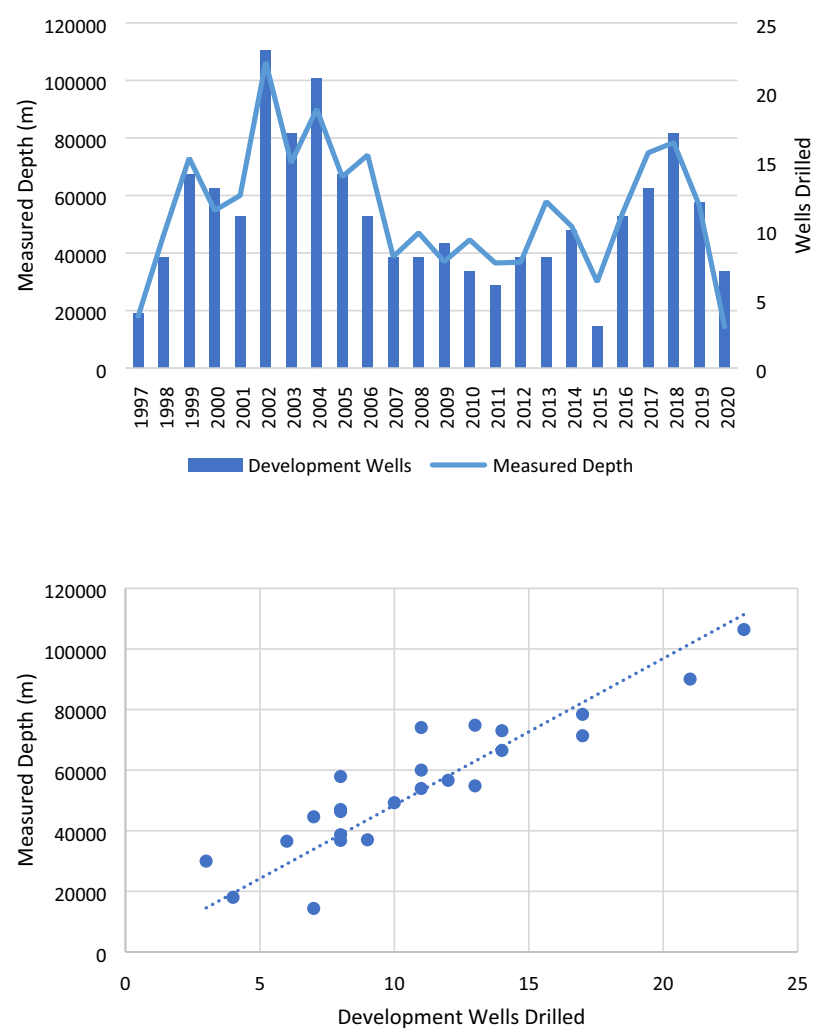

Figure 12. Relationship between amount of borehole drilled and number of development wells (top) and correlation (bottom) offshore Newfoundland, 1997-2019. Source: Data from C-NLOPB.

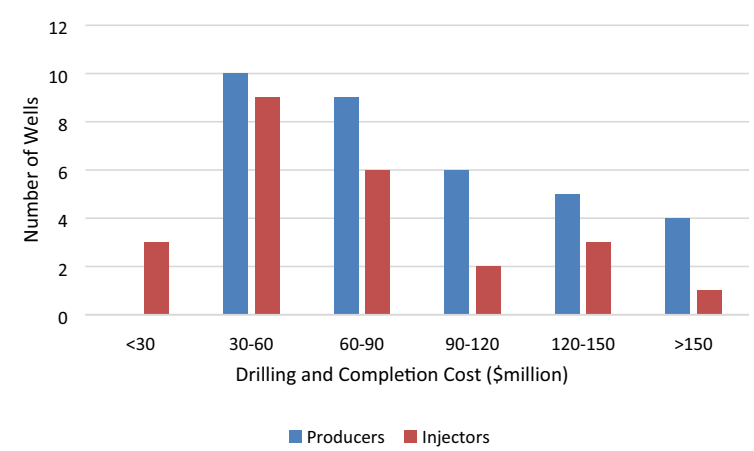

Figure 13. Development cost distribution for production and injection wells from FPSO developments offshore Newfoundland, 1999-2019. Source: Data from C-NLOPB.

\section{PRODUCTION AND RESERVES}

Through February 2020, 1.94 billion barrels (308 million $\mathrm{m}^{3}$ ) of crude oil and 3.14 trillion cubic feet $\left(88.2\right.$ billion $\left.\mathrm{m}^{3}\right)$ of natural gas have been produced offshore Newfoundland (Table 3; Fig. 15).
Production peaked in 2007 at 134 million barrels (MMbbl) or 368,000 barrels of oil per day (bopd) [21 million $\mathrm{m}^{3}$ or $\left.58,400 \mathrm{~m}^{3} / \mathrm{d}\right]$.

Natural gas associated with oil production is not a sales product and, after fuel use and gas lift, is compressed and reinjected for pressure maintenance and potential later extraction. Some gas is flared for safety purposes. A significant amount of water is also produced with black oil reservoirs, and 1.25 billion barrels $\left(198\right.$ million $\mathrm{m}^{3}$ ) was separated and treated through February 2020 (Table 3). Oil and water production tends to correlate with one another in aquifer drive ${ }^{16}$ reservoirs after a period (Fig. 16) and is readily observed at individual fields (Fig. 17).

\footnotetext{
${ }^{16}$ In water drive reservoirs, the oil and gas reservoirs reside on top of a water section called the aquifer. The aquifer can be large, many times the size of the oil- or gas-bearing reservoir, or it can be small in which the water pressure will exhaust itself before another drainage mechanism arises. If the aquifer is large, water expansion will last a long time and displace a large portion of the oil and gas before wells water out.
} 
Table 2. Development well cost statistics at Terra Nova, White Rose, and North Amethyst, 1999-2019. Source: Data from C-NLOPB

\begin{tabular}{|c|c|c|c|}
\hline & Terra Nova ${ }^{c}$ & White Rose ${ }^{c}$ & North Amethyst $\mathrm{c}^{\mathrm{c}}$ \\
\hline \multicolumn{4}{|l|}{ Production wells ${ }^{\mathrm{a}}$} \\
\hline Drilling, \$million/well & $71.5(7)$ & $71.0(17)$ & $69.6(9)$ \\
\hline Completion, \$million/well & $37.5(5)$ & $27.8(11)$ & $35.9(7)$ \\
\hline D\&C, \$million/well & $80.8(17)$ & $95.8(11)$ & $103.7(9)$ \\
\hline Drilling per meter, $\$ 1000 / \mathrm{m}$ & $16.3(7)$ & $13.0(17)$ & $13.9(9)$ \\
\hline D\&C per meter, $\$ 1000 / \mathrm{m}$ & $18.9(17)$ & $17.6(11)$ & $20.5(7)$ \\
\hline \multicolumn{4}{|l|}{ Injection wells $\mathrm{s}^{\mathrm{a}, \mathrm{b}}$} \\
\hline Drilling, \$million/well & $69.8(4)$ & $47.2(14)$ & $84.9(4)$ \\
\hline Completion, \$million/well & $18.9(1)$ & $23.2(12)$ & $30.7(4)$ \\
\hline D\&C, \$million/well & $52.0(10)$ & $84.3(12)$ & $116.1(4)$ \\
\hline Drilling per meter, $\$ 1000 / \mathrm{m}$ & $17.6(4)$ & $10.5(14)$ & $22.9(4)$ \\
\hline D\&C per meter, $\$ 1000 / \mathrm{m}$ & $11.1(10)$ & $15.1(12)$ & $31.1(4)$ \\
\hline \multicolumn{4}{|l|}{ All wells ${ }^{\mathrm{a}}$} \\
\hline Drilling, \$million/well & $70.9(11)$ & $59.0(32)$ & $74.3(13)$ \\
\hline Completion, \$million/well & $34.4(6)$ & $25.4(23)$ & $34.1(11)$ \\
\hline D\&C, \$million/well & $69.3(27)$ & $89.4(23)$ & $107.7(12)$ \\
\hline Drilling per meter, $\$ 1000 / \mathrm{m}$ & $16.8(11)$ & $11.7(32)$ & $16.7(13)$ \\
\hline D\&C per meter, $\$ 1000 / \mathrm{m}$ & $15.9(27)$ & $16.3(23)$ & $24.0(12)$ \\
\hline
\end{tabular}

${ }^{\text {a}}$ Drilling, completion, and drilling and completion (D\&C) categories are not mutually exclusive, and one well may be included in more than one category if final costs are reported in those categories. Suspended wells of indeterminate status and abandoned wells are not considered. Abandoned producer and injector well cost is included in analysis but without the abandonment cost component

${ }^{\mathrm{b}}$ Injection wells include water and gas injectors

${ }^{c}$ The first term in each column entry is the inflation-adjusted average cost in 2019 Canadian dollars, and the number in parenthesis is the sample size. Samples less than five may not be representative

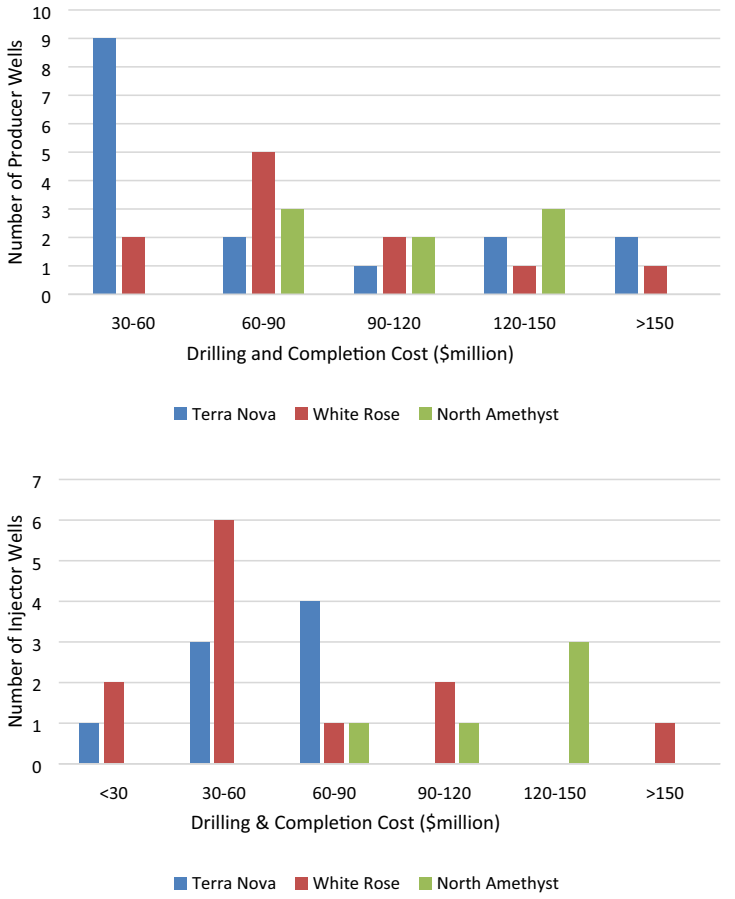

Figure 14. Drilling and completion cost distribution for producer (top) and injector (bottom) wells in FPSO developments offshore Newfoundland, 1999-2019. Source: Data from C-NLOPB.
Gas disposition and water injection totals per project through March 31, 2018, are shown in Table 4. Hebron data are not depicted because the field only came on-stream in late 2017 . Note that gas flared, fuel, and injected totals $2782 \mathrm{Bcf}$ (79 billion $\mathrm{m}^{3}$ ), and are equal to gas production, since lift gas is recirculated within the system. About $7 \%$ of gas production has been flared and another $8 \%$ used for fuel, with the remaining $85 \%$ reinjected. Gas reinjection is used to maintain reservoir pressure and displace the oil, and with the gas stored it may be recovered in the future.

Water is injected into formations for voidance replacement in aquifer drive reservoirs, and normal practice is to inject volumes approximately equal to the oil and water volumes produced. Through March 31, 2018, $1760 \mathrm{MMbbl}$ oil and $1122 \mathrm{MMbbl}$ water (279 million $\mathrm{m}^{3}$ oil and 178 million $\mathrm{m}^{3}$ water) was produced, or $2882 \mathrm{MMbbl}\left(457\right.$ million $\mathrm{m}^{3}$ ) fluids total, and 2927 MMbbl (464 million $\mathrm{m}^{3}$ ) water was injected. On a field basis, injection-to-production ratios range from 0.73 at White Rose to 1.06 at Hibernia. For additional background on produced water, water and gas injection requirements offshore, see Appendix C. 
Table 3. Cumulative production offshore Newfoundland through March 2020. Source: Data from C-NLOPB

\begin{tabular}{|c|c|c|c|c|c|}
\hline Field & Reservoir & $\begin{array}{c}\text { First } \\
\text { Production }\end{array}$ & $\begin{array}{c}\text { Oil } \\
(\mathrm{MMbbl})\end{array}$ & $\begin{array}{l}\text { Gas } \\
\text { (Bcf) }\end{array}$ & $\begin{array}{c}\text { Water } \\
(\mathrm{MMbbl})\end{array}$ \\
\hline \multirow[t]{4}{*}{ Hibernia } & Hibernia & 1997 & 1034 & 1861 & 598 \\
\hline & Avalon & 2000 & 104 & 54 & 39 \\
\hline & Catalina & 2013 & 2 & 1 & - \\
\hline & Subtotal & & 1140 & 1916 & 636 \\
\hline Hebron & Ben Nevis & 2017 & 72 & 30 & 2 \\
\hline Terra Nova & Jeanne d'Arc & 2002 & 425 & 842 & 379 \\
\hline White Rose & Ben Nevis/Avalon & 2005 & 148 & 302 & 155 \\
\hline \multirow{3}{*}{ North Amethyst } & Ben Nevis/Avalon & 2010 & 51 & 38 & 77 \\
\hline & Hibernia & 2016 & 4 & 8 & 1 \\
\hline & Subtotal & & 55 & 46 & 78 \\
\hline Total & & & 1940 & 3137 & 1249 \\
\hline
\end{tabular}

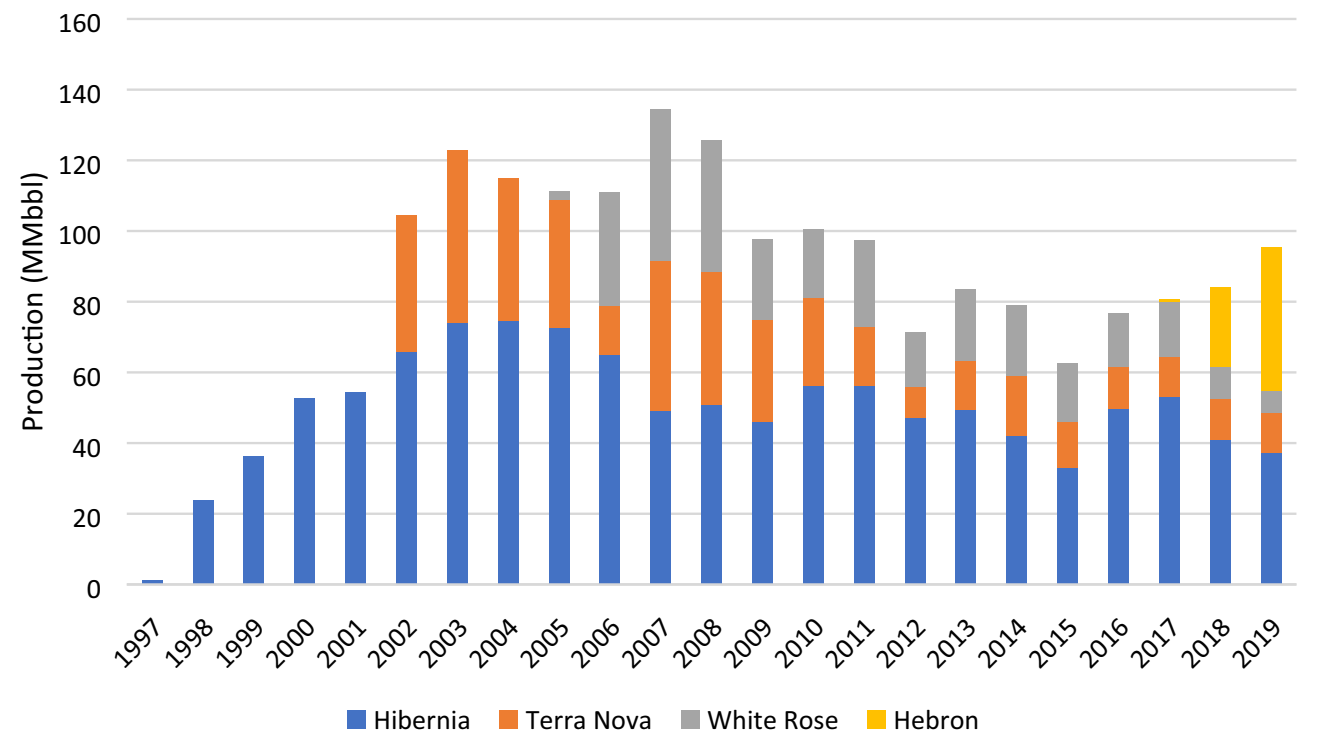

Figure 15. Oil production offshore Newfoundland, 1997-2019. Source: Data from C-NLOPB.

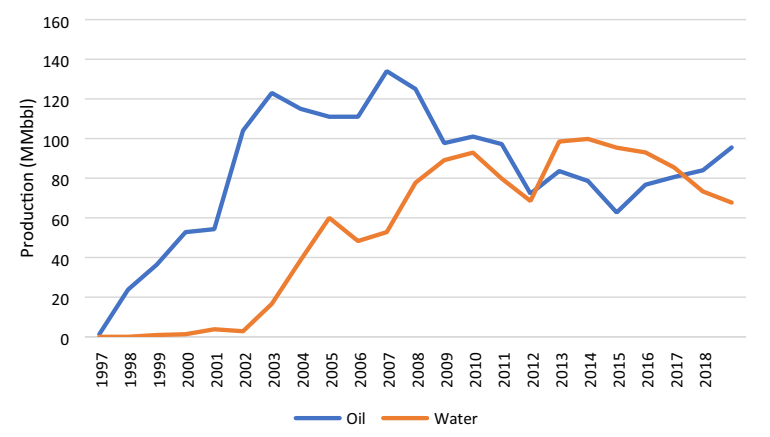

Figure 16. Total oil and produced water volumes offshore Newfoundland, 1997-2019. Source: Data from C-NLOPB.
Petroleum reserves offshore Newfoundland are estimated at 3.34 billion barrels $\left(530\right.$ million $\left.\mathrm{m}^{3}\right)$, with resources estimated at $573 \mathrm{MMbbl}$ oil, $8.3 \mathrm{Tcf}$ natural gas, and 397 MMbbl NGLs [91 million $\mathrm{m}^{3}$ oil, 235 billion $\mathrm{m}^{3}$ gas, 63 million $\mathrm{m}^{3}$ NGLs] (Table 5). The Labrador shelf is believed to have substantial gas resources, but to date discoveries have been small. The most promising areas for new discoveries are east and north of the Jeanne d'Arc basin where several deposits have been found (Fig. 2).

Equinor Canada's proposed exploration drilling project in the Flemish Pass basin was approved in 2019 (Canadian Environmental Assessment Agency 
2020a), but with the impact of Covid-19 on global oil demand and prices, these plans were in review in late 2020. Equinor Canada proposed drilling up to

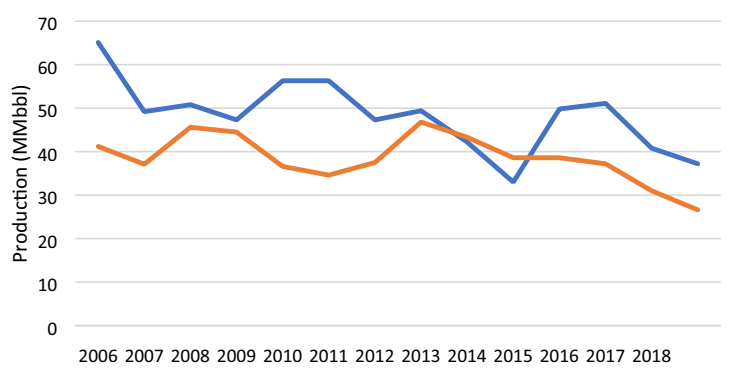
oil W Water

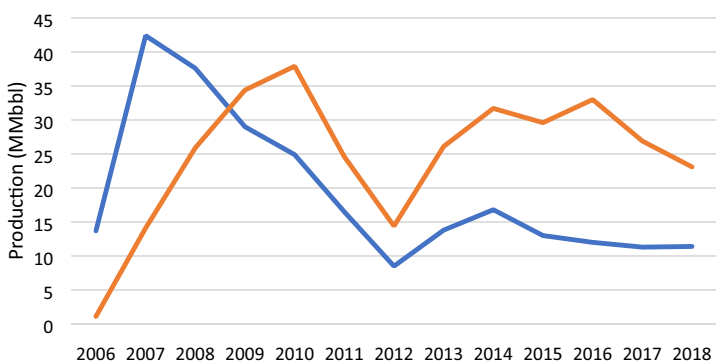
Oil Water

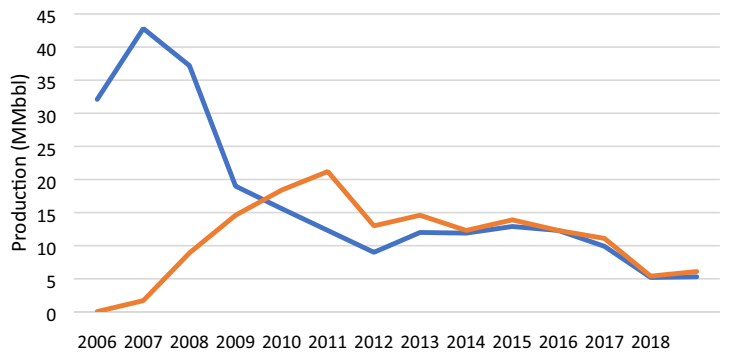

Oil Water

Figure 17. Oil and water production at Hibernia (top), Terra Nova (middle), and White Rose (bottom), 2006-2018. Source: Data from C-NLOPB.
24 offshore wells (six per exploration license) between 2019 and 2027.

In September 2020, three additional proposed projects by three different operators were under review by the Impact Assessment Agency of Canada: BHP Canada, Central Ridge and West Flemish Pass, all located approximately $350-375 \mathrm{~km}$ east of St. John's, Newfoundland (Canadian Environmental Assessment Agency 2020b). The first step of federal environmental assessment is a public consultation process and environmental evaluation. After the consultation process and environmental review is completed, if the economic and operator conditions (e.g., corporate budget) are still suitable, wells will be drilled in accordance with the drilling plans.

Table 5. Petroleum reserves and resources offshore Newfoundland and Labrador. Source: C-NLOPB Annual Report 2015-2016

\begin{tabular}{lccc}
\hline & $\begin{array}{c}\text { Oil } \\
(\mathrm{MMbbl})\end{array}$ & $\begin{array}{c}\text { Gas } \\
(\mathrm{Bcf})\end{array}$ & $\begin{array}{c}\mathrm{NGL}^{\mathrm{c}} \\
(\mathrm{MMbbl})\end{array}$ \\
\hline $\begin{array}{l}\text { Grand Banks } \\
\text { Reserves }^{\mathrm{a}}\end{array}$ & 3336 & & \\
$\begin{array}{l}\text { Resources } \\
\text { Labrador shelf } \\
\quad \text { Resources }\end{array}$ & 573 & 8322 & 397 \\
Total & & & \\
\hline
\end{tabular}

${ }^{\mathrm{a}}$ Reserves are volumes of hydrocarbon proven by drilling, testing, and interpretation of geological, geophysical, and engineering data, that are recoverable using current technology and under present and anticipated economic conditions

${ }^{\mathrm{b}}$ Resources are volumes of hydrocarbons, expressed at 50 percent probability, assessed to be technically recoverable that have not been delineated and have unknown economic viability

${ }^{\mathrm{c}}$ Natural gas liquids (NGLs) are derived from the components of natural gas that include ethane, propane, butanes, pentanes and higher, which is the portion of petroleum that exists in either the gaseous phase or in solution in crude oil in reservoirs. The light gases ethane, propane, and butanes can be made liquid by cooling and adding pressure. Naphtha and condensate are composed primarily of pentanes plus and are liquid at room temperature

Table 4. Field production statistics cumulative to March 31, 2018. Source: C-NLOPB Annual Report 2017-2018

\begin{tabular}{llcclr}
\hline Production & Unit & Hibernia & Terra Nova & White Rose/North Amethyst & Total \\
\hline Oil & MMbbl & 1067 & 406 & $236 / 51$ & 1760 \\
Gas & Bcf & 1747 & 740 & $256 / 41$ & 2784 \\
Water & MMbbl & 583 & 331 & $142 / 66$ \\
Gas disposition & & & & $36 / 4$ & 1122 \\
Flared & Bcf & 95 & 61 & $36 / 7$ & 196 \\
Fuel & Bcf & 108 & 67 & $183 / 30$ & 218 \\
Injected & Bcf & 1544 & 611 & $105 / 43$ & 2368 \\
Lift & Bcf & 6 & 120 & $515 / 129$ & 2927 \\
Water injected & MMbbl & 1558 & 725 & \\
\hline
\end{tabular}




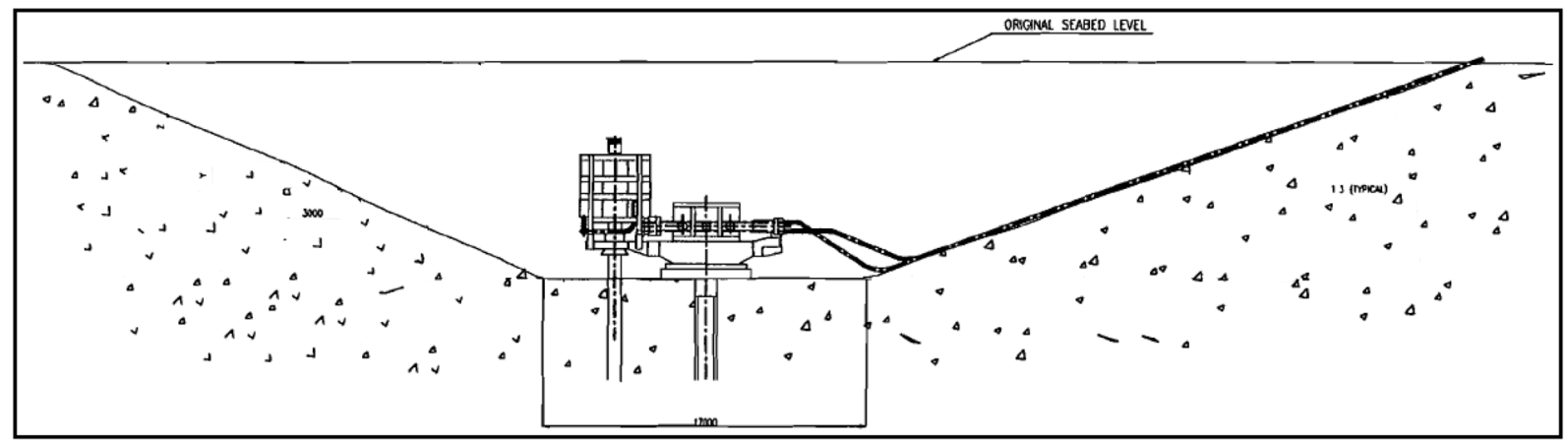

Figure 18. Cross section of glory hole at Terra Nova. Source: SUT 1998.

\section{DEVELOPMENT TRADE-OFFS}

\section{Development Plan}

The number and type of development well are key design parameters in every offshore development. Engineers determine how wide wells should be spaced without suffering any significant loss of reserves. Major fields will usually have many productive fault blocks and numerous pay sands and require dozens of wells to develop. Reservoir sands that are deep and compact will require a smaller number of wells than a thin reservoir that is spread over a large areal extent. If there are faults and reservoirs are isolated, more wells will be required to reach these locations. Development drilling will occur throughout a field's life as producing zones are plugged back and sidetracks drilled. Phased developments are often the preferred strategy for complex reservoirs or where the operator wants to limit initial development costs. The depletion plan of some developments may feature wells whose service changes during the life of the field, e.g., production wells converting to injection wells, water injection wells converting to gas injection, and in a few cases, delineation wells repurposed for development.

Development wells are more complex than exploration wells and usually more expensive to drill, not only because of their trajectories but because they must be completed (readied for produc-

\footnotetext{
${ }^{17}$ Three-dimensional wells are drilled outside a vertical plane and make one or more azimuthal turns in their trajectory. An extended reach well has a long offset relative to vertical depth, usually defined by the horizontal displacement (HD) to total vertical depth (TVD) ratio greater than two, HD/TVD $>2$. Extended reach wells are expensive to drill and require high-spec rigs and state-of-the-art technology, and extensive planning and risk management (Paila et al. 2019).
}

tion), and for complex completions cost can be as large as drilling. Horizontal wells, usually defined by an angle at least $80 \%$ to the vertical, typically cost at least twice as much as vertical wells per meter. Three-dimensional and extended reach well ${ }^{17}$ cost may be up to five times as much as a directional well of the same length. Most offshore development wells drilled from a platform rig are directional, and because many wells are drilled in sequence, learning occurs, and performance typically improves.

\section{Dry Tree vs. Wet Tree Wells}

A dry tree well has its tree ${ }^{18}$ above the waterline and is accessible from the platform, allowing direct access from a platform rig or MODU. Production from dry tree wells flows from the reservoir through the conductor to the rig floor. Wet (subsea) wells have their trees located on the seafloor, either directly below the platform or offset from the platform. In iceberg-prone areas in water depth less than $100 \mathrm{~m}$, wet wells are placed in excavated glory holes $^{19}$ to protect the wellheads and trees from scouring icebergs (Fig. 18). A MODU is needed to access subsea wells, and flowlines/risers are used to transport production to the facility for processing.

There is no subsea infrastructure cost for dry tree wells but major construction and completion challenges to overcome in reaching target using

\footnotetext{
${ }^{18}$ Trees (also called Christmas trees) are located on the top of each well and function as a flow control device and injection point for chemicals that enter the well, reservoir, and flowline.

${ }^{19}$ In shallow water, glory hole areas are dredged to a depth of 10 $15 \mathrm{~m}$ below the seabed to provide adequate cover to subsea equipment. In deeper water, glory holes for subsea wells are not needed since icebergs cannot grow to a size to scour the seabed.
} 
directional and extended reach wells. Dry tree wells allow easy access for maintenance and repair, as well as for future sidetracking operations. In comparison with wet tree wells, dry tree wells have lower life cycle operating cost and can extract more resource because of the ability to intervene in the well on an as-needed basis at minimal cost (Reid et al. 2013).

Subsea wells are more expensive to equip, workover, operate, and decommission than dry tree wells and will be abandoned at a higher production rate, for all things equal, because of the back pressure that arises delivering the fluid to the host and less frequent interventions to maintain the well's productivity. For empirical data on the difference between dry tree and wet tree economic limits in the deepwater US Gulf of Mexico, see Kaiser and Narra (2019). Subsea wells also have greater difficulty flowing with high water cuts because of hydrate formation, and if gas lift or subsea compression is used to flow to a lower abandonment pressure, flow assurance issues may result.

For subsea wells, the number and location of drill centers is a compromise between drilling operations, flow assurance, subsea cost, and future development. Access to the wellbore is only available from a MODU mobilization, which is expensive and can hinder reservoir development. Flow assurance is a significant operational issue and complication since fluid must be transported along (or underneath) the seafloor in flowlines to reach the host. Flow assurance requires use of chemicals, electrohydraulics for control, and regular pigging operations that increase operational cost and complexity. All reinjected fluids must also be transported in flowlines along the seabed.

\section{GBS VS. FPSO}

A gravity-base structure is a structure capable of withstanding the environmental forces to which it is exposed during its lifetime by its own weight. Gravity platforms may be built of concrete or steel or a combination of the two, but most of the gravity structures constructed for oil and gas development are concrete and are stabilized by skirts that penetrate the seabed. Concrete GBSs have a large footprint to minimize soil-bearing loads and, to provide buoyancy for transportation, have large enclosed volumes which can be used to store oil and other liquids. GBS developments in an iceberg environment are designed to withstand icebergs up to a

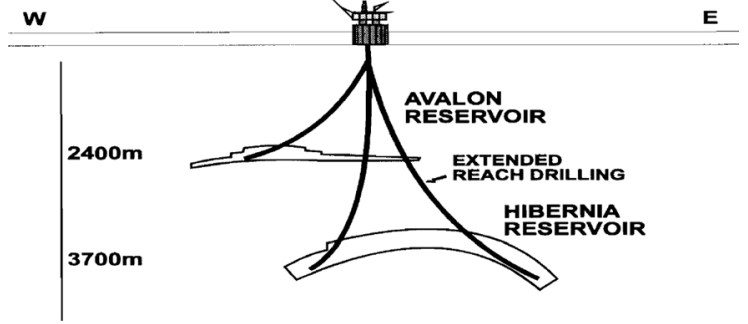

Figure 19. Depth chart of Hibernia and Ben Nevis reservoirs at the Hibernia field development.

specific mass limit (Widinato et al. 2013) and minor coverage of pack ice; if pack ice coverage is prevalent and thick, a protective berm or similar requirement will be needed like at Kashagan (Kaiser 2021).

Most GBS designs have a base caisson for oil storage and shafts penetrating the water surface to give support for the topside structures, and to serve for drilling, risers, and utility systems for offloading and ballast operations. In the first generation of GBSs, grout was normally placed under the platform to secure full contact between underside and seabed, but in the second generation of GBSs, more sophisticated systems were employed including potential refloat (Hjelde 2004).

FPSO facilities comprise a ship-shaped vessel held on location by a mooring system anchored to the seabed. If an FPSO operates in a hurricane or iceberg-prone area, the vessel may be specified with a disconnectable turret ${ }^{20}$ to allow the FPSO to disconnect from its wells and move offsite. Well fluid is transferred using flowlines and risers and is processed by equipment mounted on the deck. Produced oil is stored in tanks in the hull, awaiting transfer to shuttle tankers through an offloading system. If water and gas injection is employed, it will be treated onboard the vessel and then transferred via risers/flowlines to the reservoir.

The most important distinction between GBS and FPSO development concepts is how drilling is performed. GBS developments allow the use of dry

\footnotetext{
${ }^{20}$ Turret systems generally provide four main functions: (i) weather vaning, (ii) disconnection and reconnection between the FPSO and its moorings and risers, (iii) fluid transfer systems to and from the wells and facility, and (iv) interface for control systems and utilities for subsea systems. In weather vaning, the vessel rotates around the turret to take up a position of least resistance to the weather with the bow heading into the prevailing wind and waves assisted by thrusters.
} 
tree wells drilled and completed from a platform rig and can also use wet wells if reservoir targets are beyond the capability of the platform rigs, whereas FPSOs do not allow drilling (or workovers) from the vessel and require subsea (wet tree) wells drilled and completed from a MODU. A GBS for drilling can be used in conjunction with an FPSO to obtain the benefit of dry tree wells.

Subsea facilities at each drill center incorporate manifold systems to comingle the flow from the production wells, distribute gas lift to the production wells, and distribute water and produced gas to the water and gas injection wells. Divers and/or remotely operated vehicle (ROV) technology with marine vessels are used for maintenance, repair, and retrieval of the subsea production system.

Subsea chemical injection is achieved using umbilicals from the host transporting methanol, scale inhibitor, asphaltene inhibitor, and wax inhibitor/dissolver to the drill centers. Methanol is normally injected at the Christmas tree, while production chemicals can be injected either at the tree or downhole. Deaerated seawater is injected into oil zones for pressure maintenance. Electrohydraulic umbilicals to each manifold convey the required hydraulic fluid, chemicals, power, and communication signals necessary to operate the tree valves and monitor downhole and tree-mounted instrumentation.

\section{PROJECTS}

\section{Hibernia}

The Hibernia field was discovered in 1979 and delineated by nine wells over 5 years (Smith 1997). The two main reservoirs, the Hibernia and the Ben Nevis/Avalon, are located at average depths of 3700 and $2400 \mathrm{~m}$, respectively (Fig. 19), with the Hibernia reservoir estimated to contain over $80 \%$ of the recoverable oil. From the onset, the project was expected to require frequent wellbore intervention and extended reach wells, thus strongly favoring a GBS development despite higher investment cost (Elsborg et al. 2005).

\footnotetext{
${ }^{21}$ The largest iceberg that could approach the platform is estimated to weigh 6 million tonnes and occur once every 10,000 years. Smaller icebergs weighing 1 million tonnes are estimated to occur once every 500 years.
}

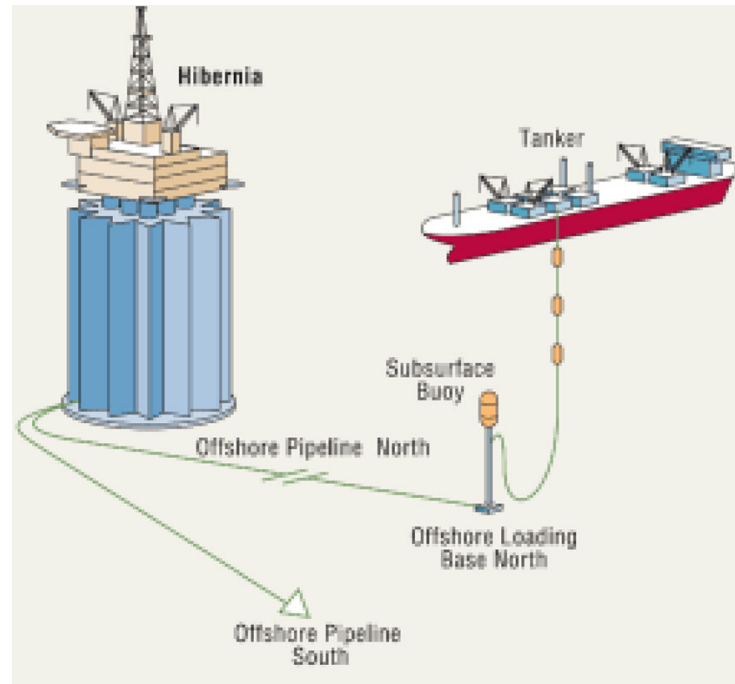

Figure 20. Hibernia field development and offloading system schematic. Source: SEC.

The Hibernia GBS is a cylindrical concrete caisson that extends from the seabed to $5 \mathrm{~m}$ above the waterline and designed to resist an iceberg impact up to 6 million tonnes ${ }^{21}$ (Fig. 20). Four shafts extend $26 \mathrm{~m}$ above the caisson to support the deck and topsides weighing 60,000 t. The platform stands $224 \mathrm{~m}$ high, which is half the height of New York's Empire State Building (449 m), and topsides facilities allow simultaneous drilling and production. Accommodations are for $185-270$ personnel (Table 6).

A 15-m thick ice wall forms the perimeter of the caisson and has 16 teeth designed to dissipate the impact energy of an iceberg to an interior tie wall (Fig. 21). The cells of the wall are filled with sea water and solid ballast. There are two drill shafts, a riser shaft, and a utility shaft; the utility shaft is permanently dry. The shafts are connected with walls and compartmentalize the interior of the caisson into six oil storage cells of $207,000 \mathrm{~m}^{3}$ (1.3 MMbbl) capacity.

The Hibernia Southern Extension is a subsea development about $7 \mathrm{~km}$ southeast of the GBS that included five production wells and six water injection subsea wells for pressure support. The production wells were drilled from the GBS platform rigs, and the injection ${ }^{22}$ subsea wells were drilled by a MODU.

\footnotetext{
${ }^{22}$ The injection wells were drilled straight down to target using relatively simple designs.
} 
Table 6. Offshore Newfoundland production facility equipment capacity. Source: Industry publications

\begin{tabular}{lllll}
\hline Capacity & Hibernia & Terra Nova & White Rose & Hebron \\
\hline Oil (Mbpd) & 230 & 150 & 140 & 150 \\
Produced water (Mbpd) & 250 & 135 & 175 & 283 \\
Water injection (Mbpd) & 300 & 180 & 280 & 370 \\
Gas compression (MMcfpd) & 200 & 260 & 200 & 235 \\
Power (MW) & 90 & 90 & 90 & 98 \\
Person on board (\#) & $185-270$ & $80-100$ & $90-110$ & $220-330$ \\
Storage capacity (Mbbl) & 1300 & 960 & 850 & 1200 \\
\hline
\end{tabular}

Equipment capacity is the latest year reported and may change over time as production requirements change. Most offshore equipment can be expanded by replacement or removing bottlenecks

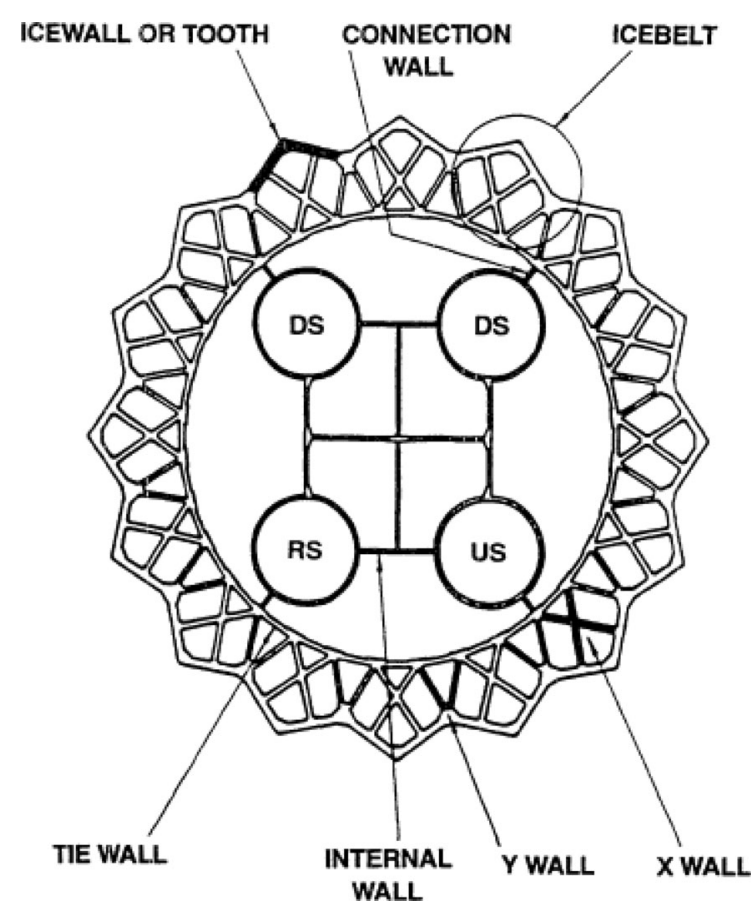

Figure 21. Ice belt, shafts for drilling and utilities, and oil storage compartments. Source: Hoff et al. (1994).

The Hibernia reservoir is highly faulted and consists of multiple, stacked fluvial channels and sand bars. A total of 64 well slots are available, and circa 2020 almost all of these were in use (Fig. 22). Most fault blocks have been developed with remaining targets including smaller blocks and infill well opportunities (Lawrence et al. 2013). At the time of drilling, Hibernia wells expanded the extended reach envelope of the industry and continue to expand the envelope as shown in Figure 23 (Woodfine et al. 2011). Drilling cost generally increases with HD/TVD ratio, but many other factors

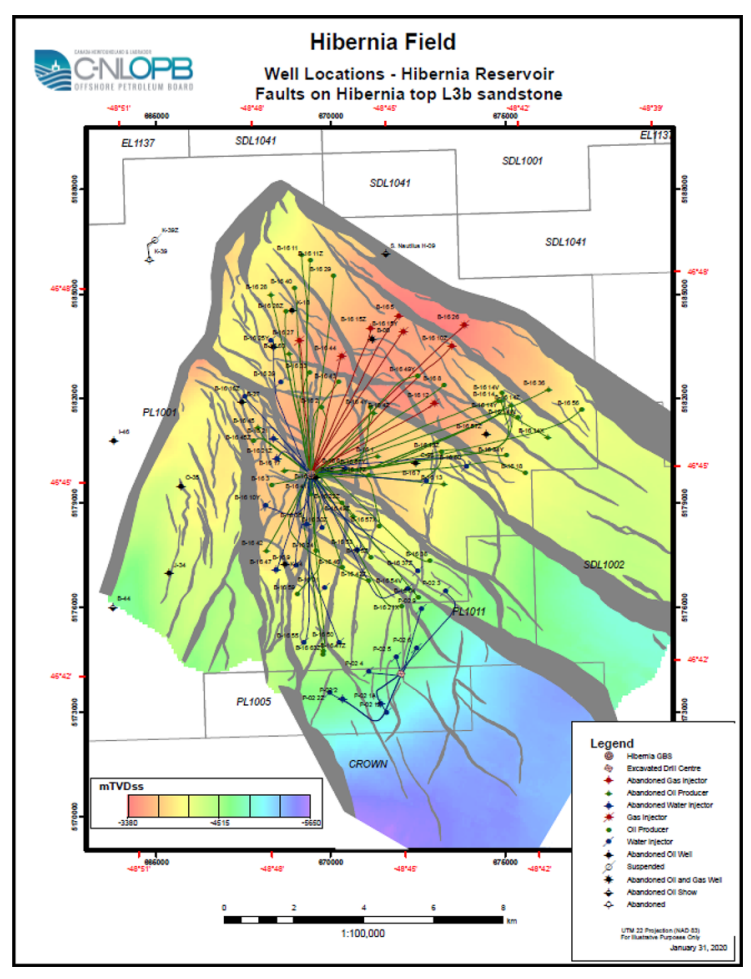

Figure 22. Hibernia field well locations, Hibernia reservoir. Faults on Hibernia top L3b sandstone. Source: C-NLOPB.

are also involved in well construction cost (Kaiser and Pulsipher 2007).

A combination of water flooding and gas reinjection is used to maximize recovery and is common to all projects in the region. Oil is transferred from the platform to shuttle tankers via an offshore loading system which consists of subsea pipelines, a subsurface buoy, and flexible loading hoses. Two tankers with a cargo capacity of 850,000 barrels $\left(135,000 \mathrm{~m}^{3}\right)$ are used to ship crude directly to market or to a transshipment terminal located in Placentia Bay, Newfoundland. 


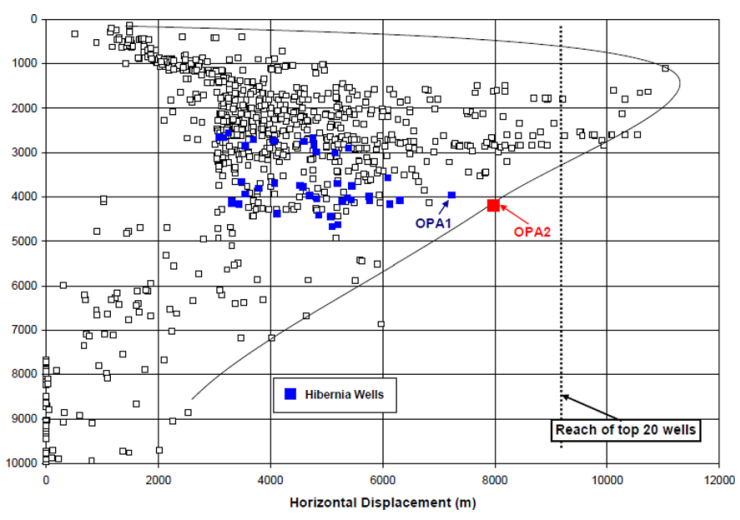

Figure 23. Extended reach drilling at Hibernia circa 2011 relative to world database showing total vertical depth versus horizontal displacement in meters. Source: Hibernia Management and Development Company.

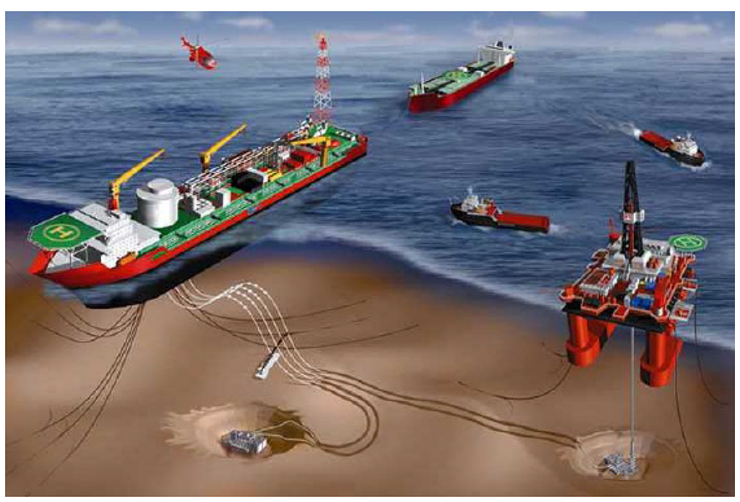

Figure 24. Terra Nova development schematic with subsea tiebacks and glory holes. Source: Suncor.
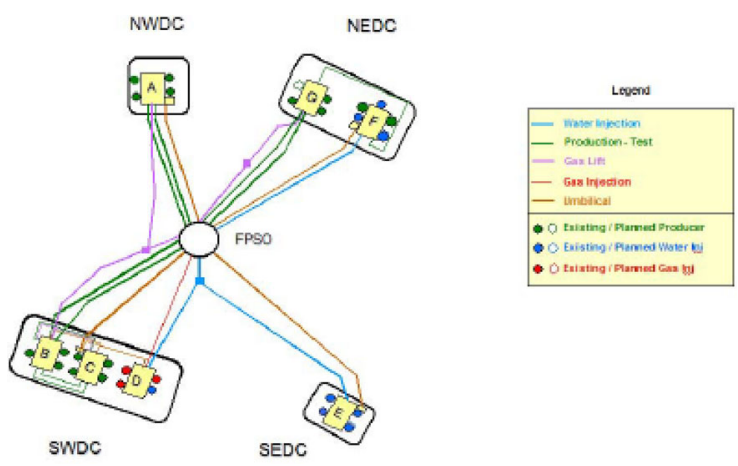

Figure 25. Terra Nova subsea layout. Source: Suncor.

\section{Terra Nova}

The Terra Nova development is based on subsea tieback wells drilled in excavated glory holes and tied back to a double-hulled ice-strengthened FPSO

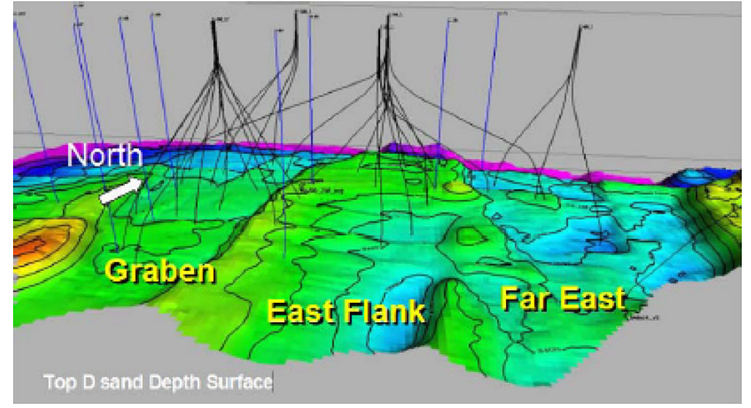

Figure 26. Terra Nova major fault blocks. Source: Suncor.

vessel using flexible flowlines/risers (Fig. 24). Four drill centers called North West (NWDC), South West (SWDC), North East (NEDC), and South East (SEDC) are employed, each approximately $5 \mathrm{~km}$ away from the FPSO (Fig. 25). The colored lines in Fig. 25 indicate the type of flowline as production, gas lift, water injection, gas lift. The SE drill center is for water injection only (Haugen et al. 2007).

The field is divided by faults into more than two dozen connected tank units, and most units or fault blocks hold an injector-producer well pair (Stephens et al. 2000). Most of the producer wells are deviated, and most injectors are vertical or close to vertical (Fig. 26). Three long reach wells have $4-5 \mathrm{~km}$ offset and $6-7 \mathrm{~km}$ measured depth.

The FPSO vessel has a length of $292 \mathrm{~m}$, a beam of $45.5 \mathrm{~m}$, and a depth of $28.2 \mathrm{~m}$ (Lever et al. 2001). The mooring system consists of nine anchor legs in $3 \times 3$ arrangements, each group 120 degrees apart. The FPSO has five $5 \mathrm{MW}$ thrusters, two at the bow and three at the stern, for position location and offsite movement.

The turret mooring system was designed to maintain station in the 100-year storm and to be disconnectable to avoid collision with icebergs with a mass greater than $100,000 \mathrm{t}$ or pack ice greater than $5 / 10$ coverage and $0.3 \mathrm{~m}$ thick (Howell et al. 2001). A controlled disconnect can be accomplished in waves up to $7.5 \mathrm{~m}$ significant height in $4 \mathrm{~h}$, with all risers flushed and depressurized. An emergency disconnect can be accomplished in $15 \mathrm{~min}$.

The turret is $70 \mathrm{~m}$ from the bottom of the spider buoy to the swivel stack (Fig. 27), and once the FPSO disconnects, the mooring and riser system is supported by the spider buoy at $35 \mathrm{~m}$ below sea level. At the main deck, the turret diameter is $12 \mathrm{~m}$ and at the vessel keel $22 \mathrm{~m}$. When the spider buoy is released from the lower turret, it free-falls to its design depth. 


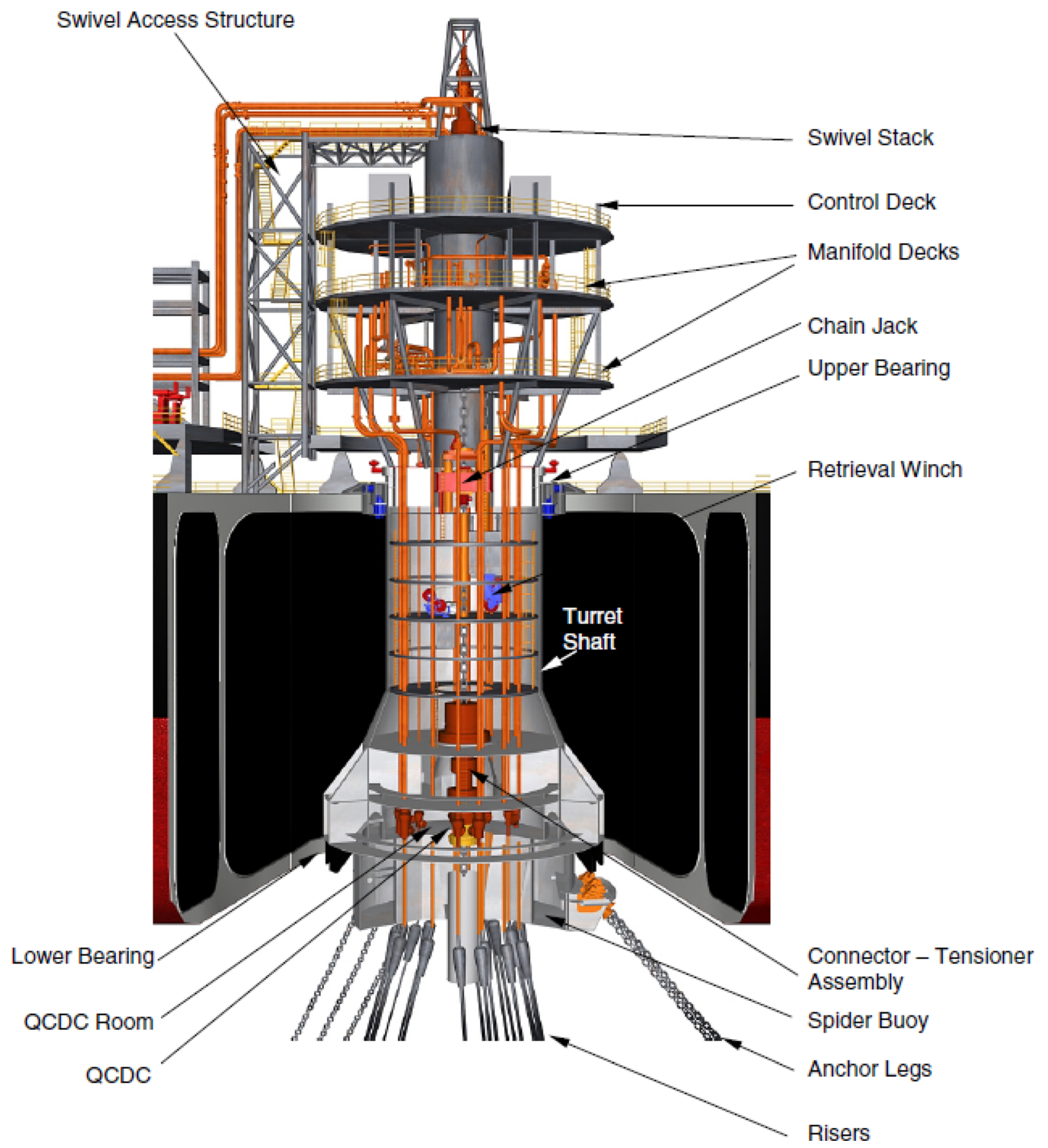

Figure 27. Terra Nova turret general arrangement. Source: Suncor.

\section{White Rose}

The White Rose development employed an FPSO facility, like that selected for Terra Nova, with glory holes and a disconnectable turret (Norman et al. 2008). Initial development required 14 pro- duction wells in the South Avalon reservoir and 11 water and gas injection wells (Pardy et al. 2013). Produced associated gas minus gas lift and fuel gas is reinjected into a gas cap in the northern part of the field to maintain reservoir pressure and for possible future extraction. The Northern pools and West 


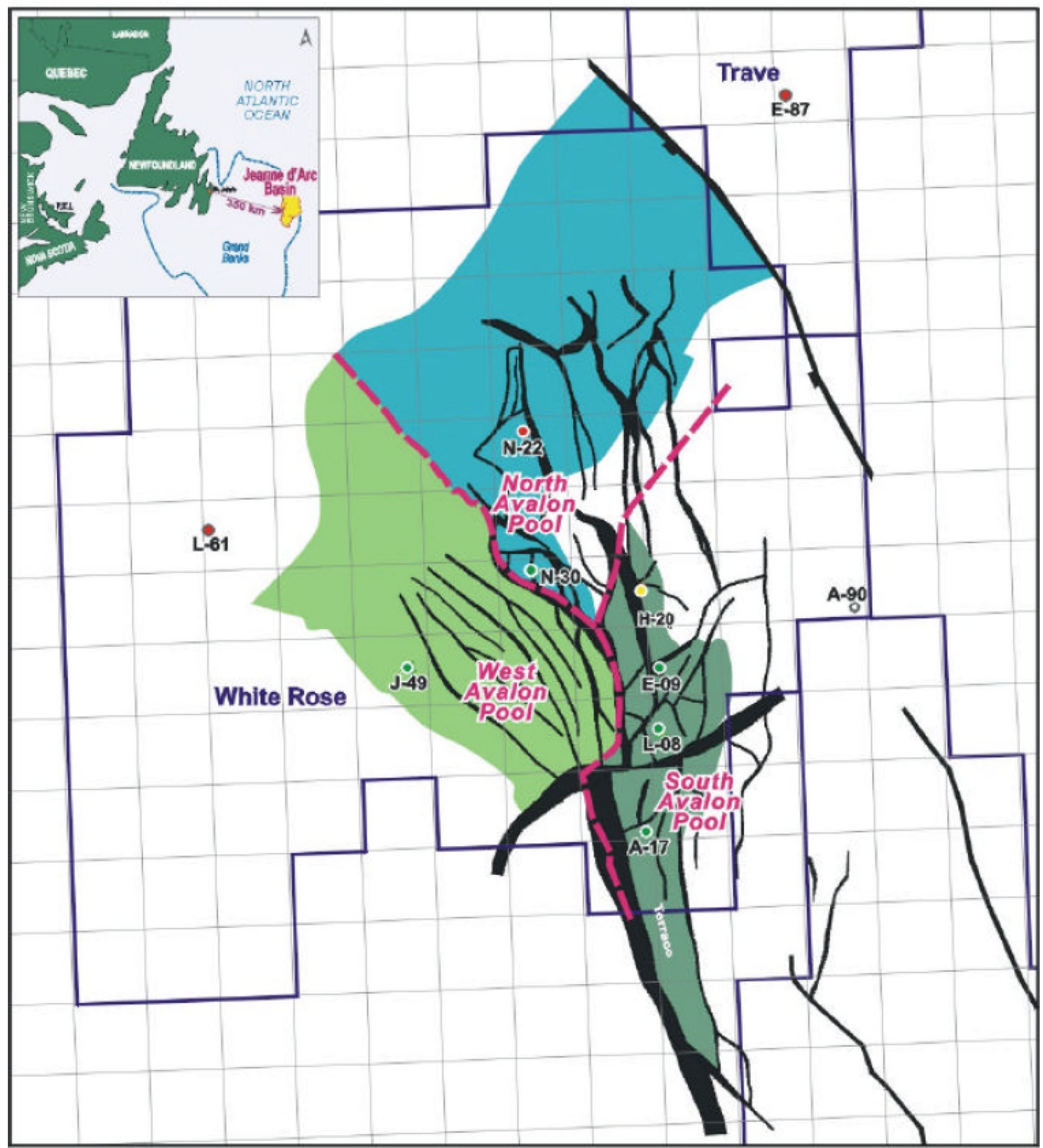

Figure 28. White Rose complex Avalon pools. Source: White Rose DA volume 2 (development plan).

Avalon extension has a thick gas accumulation and a thinner, less extensive, oil leg (Fig. 28).

The West White Rose project was proposed to access resources in the West Avalon pool using a concrete gravity wellhead platform produced back to the FPSO. The wellhead platform would host a drilling rig intended to improve drilling efficiency, lower operating costs, and extract a larger portion of the resource, but the project is currently suspended and future operations under review. If sanctioned, the concrete GBS is expected to be $145 \mathrm{~m}$ high and 


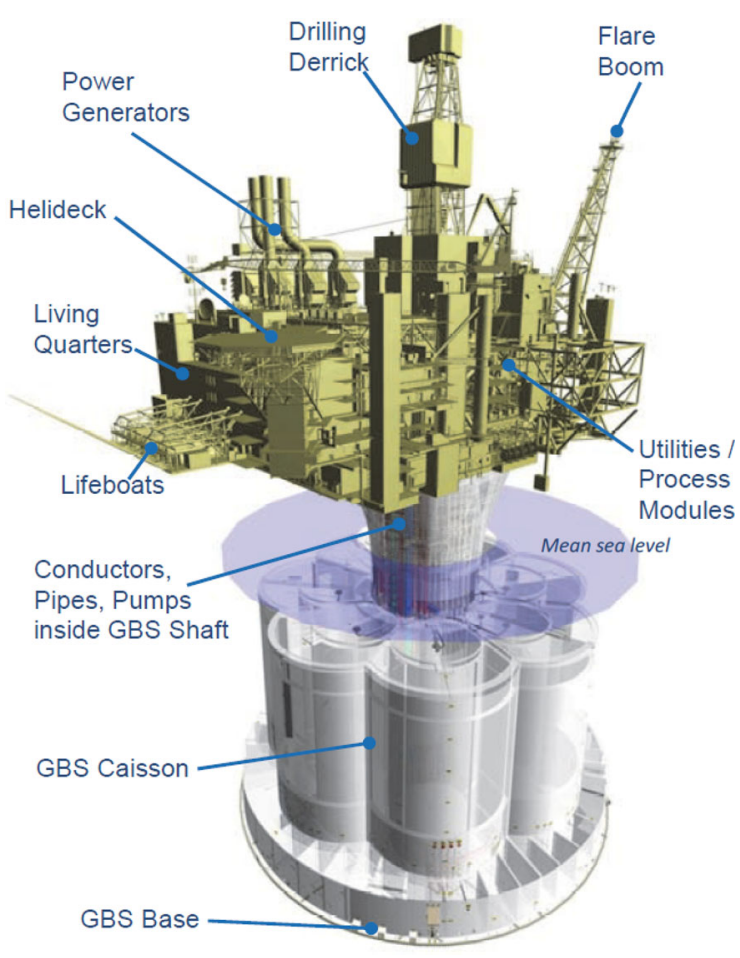

Figure 29. Hebron drilling, production and storage gravitybase structure. Source: Hebron DA volume 2 (development plan) September 2011.

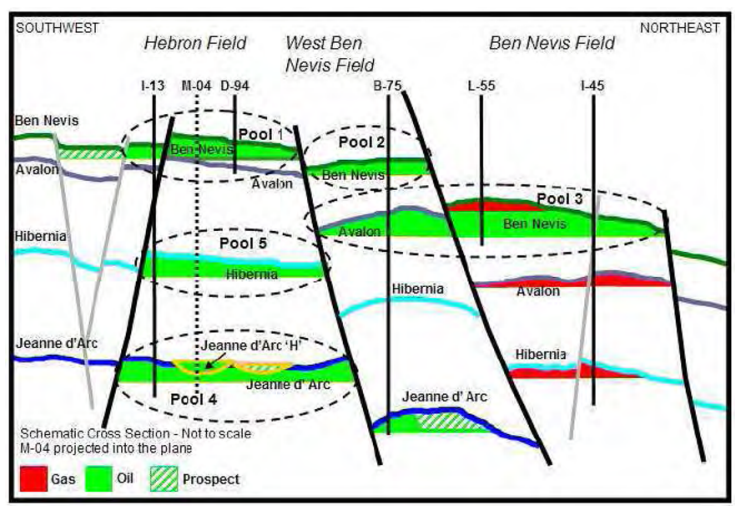

Figure 30. Schematic cross section across the Hebron project area. Source: Hebron DA volume 2 (development plan) September 2011.

weigh 210,000 tonnes, with total platform height $241 \mathrm{~m}$ and operating weight 30,000 ton.

\section{Hebron}

After initial discovery in 1980, field delineation and appraisal stretched over a period of 19 years before the decision to proceed was made in 2012 with a concrete GBS and offloading system (Fig. 29) (Wolfe et al. 2018).

Three rotated fault blocks define the structural framework of the Hebron field (Fig. 30). Within the three main fault blocks are three main reservoirs, and five hydrocarbon pools define separate accumulations (Cornaglia and McNeill 2018). The initial development phase focuses on the Hebron fault block and its three vertically separated reservoirs Ben Nevis (Pool 1), Hibernia (Pool 5), and Jeanne d'Arc (Pool 4).

The largest reservoir is the Hebron Ben Nevis reservoir unit (Pool 1) and accounts for $80 \%$ of the total recoverable project reserves. Hebron Ben $\mathrm{Ne}-$ vis reservoir oil is $20^{\circ} \mathrm{API}$, and it is significantly denser than Hibernia crude. The Hebron Hibernia reservoir (Pool 5) and Hebron Jeanne d'Arc reservoir (Pool 4) are of higher quality than Hebron Ben Nevis but more difficult to access. The Ben Nevis reservoir (Pool 3) is expected to be developed as a subsea tieback at a later date.

The Pool 1 Ben Nevis reservoir is the focus of the development and requires extended reach producers drilled from the platform and completed with up to $1500-\mathrm{m}$ open-hole gravel packs to mitigate sand control issues. A series of peripheral water injectors is used in development, and solution gas will be stored in Pool 2 Ben Nevis reservoir and produced again later in field life when gas requirements exceed production from the field. The deeper Pools 4 and 5 will be developed at a later stage but are not expected to contribute significantly to total production.

Hebron's upper wells encounter degraded reservoir properties, while the lower wells are located in the best part of the reservoir but closer to the oil-water contact, exposing them to a higher risk of early water breakthrough. To mitigate the water production rate uncertainty, the facilities were designed with robust water handling capability.

\section{DEVELOPMENT COST}

\section{Economic Measure}

Unit development cost provides a rough indication of the economic viability of a project and is a useful metric to compute prior to more advanced cash flow modeling (Gallun et al. 2001). There are several ways to compute unit development cost, but 
probably the most common method combines estimated total capital spending plus operating costs over the production life cycle divided by the expected ultimate recoverable reserves (EUR):

$$
\frac{\text { Capital spending }+ \text { Operating expenditures }}{\text { Expected ultimate recoverable reserves }} \text {. }
$$

All quantities in both numerator and denominator are expected values at the time of evaluation, usually project sanction or near the start of production, but can also occur later when better estimates are available. Capital spending and operating expenditures are usually not discounted, but for comparisons, inflation adjustment is suggested.

Exploration costs are sunk costs and are usually not included in development cost metrics. EUR is usually interpreted as initial proved plus probable reserves (2P) estimated using P50 probability. At the start of development, $2 \mathrm{P}$ reserves and life cycle cost are uncertain, but with the passage of time both become better known. Near the end of production, EUR and cumulative production coincide.

On a regional level, Newfoundland unit development cost through 2020 based on the aggregate inflation-adjusted data described in the Introduction yields:

$$
\frac{(\$ 33+\$ 30) \text { billion }}{1.94 \text { Bbbl }}=\$ 32.5 / \mathrm{bbl}
$$

Life cycle development cost applies total reserves and an assumed additional $\$ 10$ billion in future production costs to yield:

$$
\frac{(\$ 33+\$ 30+\$ 10) \text { billion }}{3.3 \mathrm{Bbbl}}=\$ 22.2 / \mathrm{bbl} .
$$

At a project level, total capital and operating costs estimated by operators at the time of project sanction and adjusted to 2019 ranged from $\$ 4.8$ billion at White Rose to $\$ 16.6$ billion at Hebron (Table 7). The capital expenditures for GBS structures are two to three times greater than FPSO vessels. For Hibernia, life cycle operating cost is less than half of capital cost, but for Hebron, costs escalated to over two-thirds capital cost. Larger projects with greater reserves are expected to have lower unit development cost, but variability is large (Table 8). Unit development cost ranged from $\$ 8 /$ bbl (Hibernia) to $\$ 24 /$ bbl (Hebron).

\section{Spending Plans}

Operators sometimes report capital spending and operating cost estimates in development plans submitted to regulators. In the absence of better information, these data may be matched against actual activity levels, but appropriate caution should be exercised in interpreting results since this is a gross approximation based on unverified data that is potentially unreliable.

For example, comparing White Rose capital spending estimates shown in Table 9 with the actual number of wells drilled during the time period leads to an inferred cost of $\$ 35$ million per development well (unadjusted) and a life cycle production cost (excluding transportation cost) of $\$ 4.2 / \mathrm{bbl}$. These well cost estimates are about two to three times less than the actual development costs shown in Table 2. Hebron operating expenditures shown in Table 10 leads to a production cost estimate of $\$ 9.8 / \mathrm{bbl}$.

ExxonMobil reported capital and expenditure cost for the Hebron GBS development and for the Pool 3 subsea $^{23}$ development (Table 11). Total construction cost for the GBS was estimated at about $\$ 6.5$ billion, development wells cost $\$ 1.9$ billion, and life cycle production cost $\$ 5.9$ billion. Using this information, along with the reported/expected 19 producing wells and 7 gas/water injection wells required in initial development, leads to an average unadjusted development well cost of $\$ 73$ million (\$1900 million/26 wells).

\section{EMPLOYMENT}

\section{Labor}

Labor costs in offshore oil and gas operations are a significant expense (Kaiser 2019). Labor costs include the salary of employees who are directly involved in production activities, services such as general repairs and maintenance, and supervision. Payroll and benefits for corporate staff are usually not included, but employee benefits, such as insurance and medical service, may be included (Gallun

\footnotetext{
${ }^{23}$ Pool 3 reserves are expected to be tied back to the GBS at a cost of $\$ 1.7$ billion in construction and $\$ 1.8$ billion in development drilling. Operations cost depend upon the timing of first production and are likely to be incremental if overlapping with the GBS production.
} 
Table 7. Capital and operating cost estimates in million Canadian dollars ${ }^{\mathrm{a}}$ at time of project sanction and inflation adjusted to 2019

\begin{tabular}{|c|c|c|c|c|}
\hline & Hibernia & Terra Nova & White Rose ${ }^{\mathrm{b}}$ & Hebron $^{\mathrm{C}}$ \\
\hline Administration & & & 30 & 1575 \\
\hline Drilling & 1000 & & 700 & 1887 \\
\hline Facilities & $4400^{\mathrm{d}}$ & & 1114 & $4873^{d}$ \\
\hline Subsea & & & 314 & \\
\hline Total capital costs & 5400 & 2600 & 2158 & 8334 \\
\hline Operating costs & 2600 & 1900 & 1177 & 5883 \\
\hline Total costs & 8000 & 4500 & 3335 & 14,217 \\
\hline Adj. capital costs ${ }^{\mathrm{e}}$ & 8640 & 3718 & 3086 & 9751 \\
\hline Adj. operating costs $\mathrm{e}^{\mathrm{e}}$ & 4160 & 2717 & 1683 & 6883 \\
\hline Adj. total costs ${ }^{\mathrm{e}}$ & 12,800 & 6435 & 4769 & 16,634 \\
\hline
\end{tabular}

${ }^{a}$ Hibernia cost reported in 1995 Canadian dollars, Terra Nova and White Rose in 2001 Canadian dollars, Hebron in 2011 Canadian dollars

${ }^{\mathrm{b}}$ See also Table 9

'See also Tables 10 and 11

${ }^{\mathrm{d}}$ Facilities include platform, topsides, and offshore loading system

${ }^{\mathrm{e}}$ Inflation-adjusted to 2019 Canadian dollars

Table 8. Unit cost metrics inflation-adjusted to 2019. Source: Project development applications

\begin{tabular}{lllll}
\hline & Hibernia & Terra Nova & White Rose & Hebron \\
\hline CAPEX (\$billion) & 8.6 & 3.7 & 3.1 & 9.8 \\
OPEX (\$billion) & 4.2 & 2.7 & 1.7 & 6.9 \\
Total cost a $^{\mathrm{a}}$ (billion) & 12.8 & 6.4 & 4.8 & 16.6 \\
EUR $^{\mathrm{b}}(\mathrm{MMbbl})$ & 1644 & 506 & $404^{\mathrm{c}}$ & 707 \\
CAPEX $^{\mathrm{d}}(\$ / \mathrm{bbl})$ & 5.2 & 7.3 & 7.7 & 13.9 \\
OPEX $^{\mathrm{d}}(\$ / \mathrm{bbl})$ & 2.6 & 5.3 & 4.2 & 9.8 \\
Total $^{\mathrm{d}}(\$ / \mathrm{bbl})$ & 7.8 & 12.6 & 11.9 & 23.7 \\
\hline
\end{tabular}

${ }^{a}$ See Table 7 for adjusted and unadjusted estimated capital and operational expenditures

${ }^{b}$ EUR c.2020, interpreted as proved plus probable reserves (2P) and P50 estimates

${ }^{\mathrm{c}}$ Does not include North Amethyst reserves or the proposed West White Rose extension

${ }^{\mathrm{d}}$ Capital expenditures and operating cost at the time of project sanction are not discounted but have been adjusted for inflation to 2019

et al. 2001). Some benefits are required by local laws and benefit packages vary by company.

All producing facilities offshore Newfoundland are manned $24 \mathrm{~h}$ a day by two crews working on 12$\mathrm{h}$ shifts on a 14- or 21-day schedule. During well intervention and drilling operations or significant upgrades, head counts will increase. Personnel represent a significant fixed cost associated with production and influence many other cost components such as personnel logistics and catering.

\section{Head Counts}

Operators are required to file an annual benefits report to C-NLOPB summarizing employment for operations and construction separately. At the end of 2019, the head count for oil and gas operations offshore Newfoundland totaled 4520-Hibernia had a head count of 1400 , Terra Nova 853, White Rose

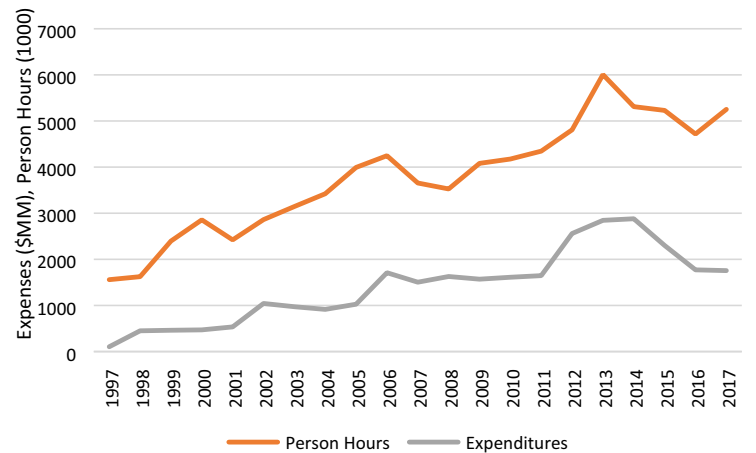

Figure 31. Total production expense and operations personhours at Newfoundland's offshore developments, 1997-2017. Source: C-NLOPB.

1105, and Hebron 1162 (Table 12). Reported persons are directly employed and include operator and contractor personnel. Personnel are typically organized into different groups such as field manage- 

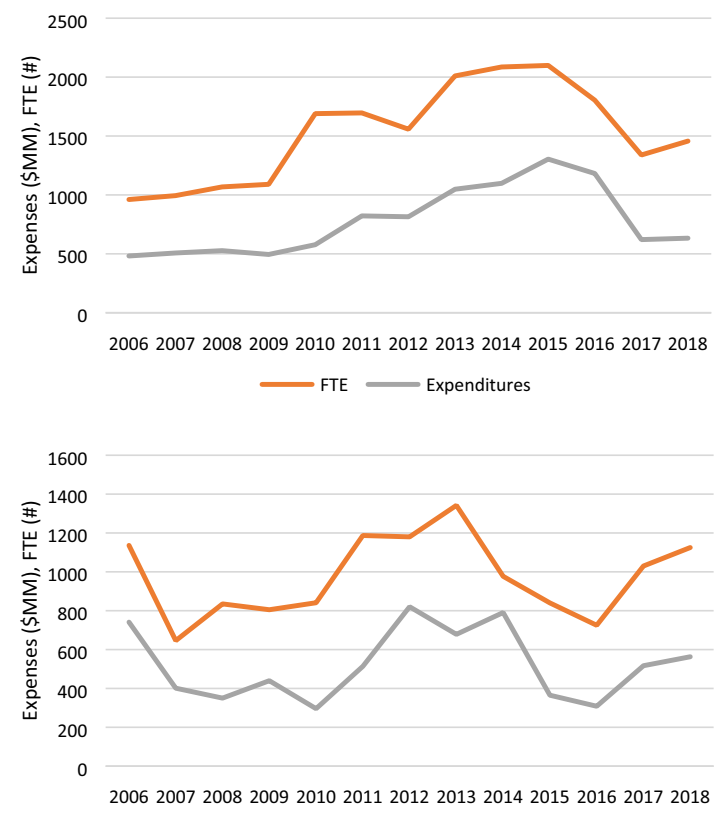

FTE Expenditures

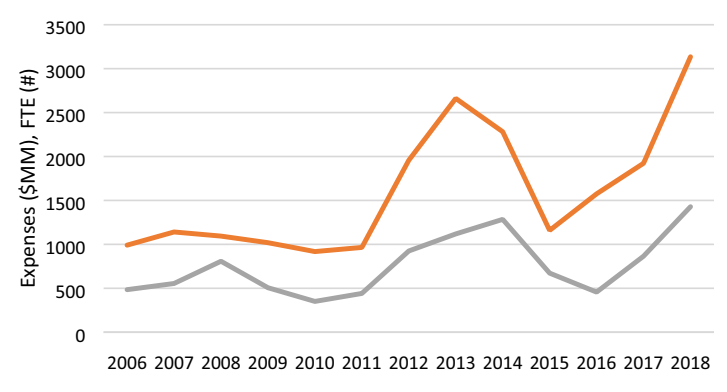

FTE Expenditures

Figure 32. Production expenditures in million dollars and head counts at the end of each reporting period; Hibernia (top), Terra Nova (middle), and White Rose (bottom), 20062018. Source: C-NLOPB.

ment, production crew, multi-skill personnel such as mechanics and electricians, roustabouts, housekeeping, and catering. Construction activity ceases with the start of operations.

Year-end head count differs from full-time equivalent data reported as person-hours because it represents a point in time as opposed to all employment activity over the full year. Onshore staffing and support for offshore operations is about the same size as offshore requirements for each producing field.

\section{Person-Hours and Head Counts vs. Production Expenditures}

In 1997, about 1.6 million person-hours were required in operations, which increased to about 5.3 million person-hours in 2017-2018 as more facilities have been installed. As one might expect, production expenditures relate to person-hours worked (Fig. 31), and robust relationships hold at individual fields using head counts (Fig. 32).

Roughly speaking, at a regional level about one-third of total person-hours worked per year approximate annual expenditures in million dollars. For producing fields, about 40 to 50 percent of total head count approximates operator expenditures in million dollars:

Expenditures $_{\mathrm{NF}}=0.37 \cdot$ Person-hours, $\mathrm{R}^{2}=0.87$.

Expenditures $_{\mathrm{Hib}}=0.47 \cdot$ Head count, $\mathrm{R}^{2}=0.75$.

Expenditures $_{\mathrm{TN}}=0.47 \cdot$ Head count, $\mathrm{R}^{2}=0.54$.

Expenditures $_{\mathrm{WR}}=0.42 \cdot$ Head count, $\mathrm{R}^{2}=0.87$.

\section{Labor Contribution to Production Expenditures}

Using 2020 workforce levels, and assuming salaries of $\$ 200,000$ for management, $\$ 150,000$ for engineers, marine crew, and skilled trades, and $\$ 100,000$ for all other employees yields a total labor cost of about $\$ 595$ million, about $25 \%$ of the total production expenditures in 2020.

\section{PRODUCTION COST}

\section{Operating Cost vs. Capital Expenditure}

Capital expenditures (CAPEX) represent the investment required to design, construct, and commission the hardware for field development, and include the wells, platforms, facilities, equipment, pipelines, and everything else with a lifetime greater than one year. CAPEX is typically defined as those items whose useful life exceeds one year, and as such, tax regulations require each item be depreciated on a specific schedule when computing net income (Gallun et al. 2001). In contrast, operating expenditures (OPEX), also referred to as lease operating expenses, lifting cost or production cost, represent items whose useful life is one year or less and costs are expensed for accounts. 
Table 9. White Rose development capital and operating cost estimates. Source: White Rose development application

\begin{tabular}{|c|c|c|c|c|c|c|c|c|}
\hline \multirow[t]{2}{*}{ Year } & \multirow{2}{*}{$\begin{array}{l}\text { Production } \\
\left(1000 \mathrm{~m}^{3}\right)\end{array}$} & \multicolumn{4}{|c|}{ Pre-production (\$million) } & \multirow{2}{*}{$\begin{array}{l}\text { Post-prod. } \\
\text { (\$million) }\end{array}$} & \multirow{2}{*}{$\begin{array}{c}\text { Total } \\
\text { (\$million) }\end{array}$} & \multirow{2}{*}{$\begin{array}{l}\text { Operating } \\
\text { (\$million) }\end{array}$} \\
\hline & & Admin. & Drilling & Facilities & Subsea & & & \\
\hline 1 & & 10 & & 111 & & & 121 & \\
\hline 2 & & 10 & 115 & 390 & 82 & & 597 & \\
\hline 3 & & 10 & 155 & 390 & 150 & & 705 & \\
\hline 4 & 4000 & & 41 & 223 & 82 & 114 & 460 & 59 \\
\hline 5 & 5340 & & & & & 155 & 155 & 83 \\
\hline 6 & 5340 & & & & & 129 & 120 & 89 \\
\hline 7 & 5340 & & & & & & & 92 \\
\hline 8 & 4780 & & & & & & & 99 \\
\hline 9 & 3160 & & & & & & & 100 \\
\hline 10 & 2060 & & & & & & & 97 \\
\hline 11 & 1480 & & & & & & & 86 \\
\hline 12 & 1150 & & & & & & & 77 \\
\hline 13 & 940 & & & & & & & 71 \\
\hline 14 & 760 & & & & & & & 63 \\
\hline 15 & 650 & & & & & & & 57 \\
\hline 16 & 570 & & & & & & & 51 \\
\hline 17 & 480 & & & & & & & 49 \\
\hline 18 & 350 & & & & & & & 104 \\
\hline \multicolumn{9}{|l|}{19} \\
\hline 20 & & & & & & & & \\
\hline Total & 36,400 & 30 & 311 & 1114 & 314 & 389 & 2158 & 1177 \\
\hline
\end{tabular}

Data reported in Canadian dollars at the time the development application was submitted and not adjusted for inflation. Operating costs exclude crude transportation costs. The final year operating costs include $\$ 41$ million for abandonment of the facility and wells. The FPSO salvage value is estimated at $\$ 40$ million

Unlike capital expenditures, operating cost is generally much less transparent, and public data come in widely different forms and quality (Kaiser 2019). Site-specific attributes need to be accounted for, most of which are not observable or known, and can only be inferred with a high degree of uncertainty. The North Sea, both the UK and Norwegian sectors, is a notable exception and provides reliable and transparent offshore operating cost data. Newfoundland production cost is much better than the U.S. Gulf of Mexico, but not as good as the North Sea because of mixing issues described below.

For offshore development, most capital expenditures occur upfront in the exploration and development stage, with facility construction/installation and development well drilling, whereas operating costs start at first production and run through the life cycle of the field. For developments where drilling requires a structure to proceed, such as occurs with GBSs, significant drilling cost will be incurred after first production. Because OPEX occurs over a longer period compared to CAPEX and its annual amounts are small in comparison, its impact to profitability is usually less significant than the schedule and cost overruns that impact CAPEX and the changes in commodity prices that occur over the life of the asset.

\section{Unit Operating Cost}

Production cost is usually defined as lifting cost plus gathering and transportation costs and may or may not include production taxes (Gallun et al. 2001). These costs are all short term, less than one year in duration, and incurred in operations. Since gathering and transportation costs and production taxes are often small on a relative basis, their inclusion or exclusion will usually not significantly impact the metric. Formally, unit operating cost is calculated as the ratio of annual operating cost divided by annual sales production on a boe or Mcfe basis:

$$
\text { Unit cost }(\$ / \text { boe })=\frac{\text { Direct operating cost }(\$)}{\text { Sales production }(\text { boe })} \text {. }
$$

If sales are exclusively or predominately oil or gas, primary production units are employed. Life cycle unit operating cost is computed using the same formula but on a cumulative undiscounted basis. 
Table 10. Hebron platform development capital and operating cost estimates. Source: Hebron development application

\begin{tabular}{|c|c|c|c|c|c|c|c|}
\hline \multirow[t]{2}{*}{ Year } & \multicolumn{4}{|c|}{ Pre-production (\$million) } & \multirow[t]{2}{*}{ Drilling } & \multirow{2}{*}{$\begin{array}{c}\text { Total } \\
\text { (\$million) }\end{array}$} & \multirow{2}{*}{$\begin{array}{l}\text { Operations } \\
\text { (\$million) }\end{array}$} \\
\hline & Admin. & Topsides & GBS & OLS & & & \\
\hline 2010 & 68 & 12 & 13 & 0 & & 93 & 1 \\
\hline 2011 & 174 & 394 & 240 & 0 & & 807 & 9 \\
\hline 2012 & 244 & 704 & 291 & 12 & & 1252 & 11 \\
\hline 2013 & 216 & 698 & 391 & 36 & & 1340 & 14 \\
\hline 2014 & 290 & 643 & 444 & 107 & & 1484 & 20 \\
\hline 2015 & 327 & 409 & 234 & 69 & & 1039 & 36 \\
\hline 2016 & 256 & & 175 & 0 & 82 & 513 & 65 \\
\hline 2017 & & & & & 222 & 222 & 157 \\
\hline 2018 & & & & & 236 & 236 & 147 \\
\hline 2019 & & & & & 242 & 242 & 148 \\
\hline 2020 & & & & & 242 & 242 & 174 \\
\hline 2021 & & & & & 242 & 242 & 159 \\
\hline 2022 & & & & & 218 & 218 & 159 \\
\hline 2023 & & & & & 189 & 189 & 159 \\
\hline 2024 & & & & & 215 & 215 & 179 \\
\hline 2025 & & & & & & & 159 \\
\hline 2026 & & & & & & & 161 \\
\hline 2027 & & & & & & & 164 \\
\hline 2028 & & & & & & & 187 \\
\hline 2029 & & & & & & & 176 \\
\hline 2030 & & & & & & & 196 \\
\hline 2031 & & & & & & & 194 \\
\hline 2032 & & & & & & & 210 \\
\hline 2033 & & & & & & & 190 \\
\hline 2034 & & & & & & & 188 \\
\hline 2035 & & & & & & & 186 \\
\hline 2036 & & & & & & & 202 \\
\hline 2037 & & & & & & & 182 \\
\hline 2038 & & & & & & & 181 \\
\hline 2039 & & & & & & & 179 \\
\hline 2040 & & & & & & & 197 \\
\hline 2041 & & & & & & & 180 \\
\hline 2042 & & & & & & & 180 \\
\hline 2043 & & & & & & & 180 \\
\hline 2044 & & & & & & & 187 \\
\hline 2045 & & & & & & & 176 \\
\hline 2046 & & & & & & & 592 \\
\hline Total & 1575 & 2861 & 1788 & 224 & 1887 & 8334 & 5883 \\
\hline
\end{tabular}

Data reported in Canadian dollars at the time the development application was submitted and not adjusted for inflation. Operating costs exclude crude transportation costs. The final year operating costs include $\$ 430$ million for abandonment of the facility and wells

Table 11. Hebron costs with Pool 3 development in million dollars. Source: Hebron development application

\begin{tabular}{lrcccccr}
\hline & Admin. & Topsides & GBS & OLS & Construction & Drilling & Operations \\
\hline GBS & 1575 & 2881 & 1788 & 224 & 6468 & 1887 & 5883 \\
Pool 3 & 250 & 465 & 1015 & & 1730 & 1780 & 567 \\
Total & 1825 & 3346 & 2803 & 224 & 8198 & 5883 \\
\hline
\end{tabular}

Data reported in Canadian dollars at the time the development application was submitted and not adjusted for inflation. OLS $=$ offshore loading system. Construction $=$ Admin + Topsides + GBS + OLS 
Table 12. Project employment as of December 31, 2019. Source: Canada-Newfoundland and Labrador benefits reports

\begin{tabular}{|c|c|c|c|c|c|}
\hline Occupation & Hibernia & Terra Nova & White Rose & Hebron & Total \\
\hline Administration & 80 & 65 & 56 & 55 & 256 \\
\hline Engineers & 135 & 151 & 146 & 100 & 532 \\
\hline Management & 169 & 91 & 67 & 117 & 444 \\
\hline Marine crew & & 126 & 205 & & 331 \\
\hline Other field services & 219 & 70 & 120 & 22 & 431 \\
\hline Professionals & 223 & 103 & 224 & 198 & 748 \\
\hline Skilled trades & 337 & 138 & 110 & 316 & 901 \\
\hline Technicians & 150 & 92 & 177 & 151 & 570 \\
\hline Other & 265 & & & & 265 \\
\hline Total & 1400 & 853 & 1105 & 1162 & 4520 \\
\hline
\end{tabular}

\section{Normalized Production Expenditures}

C-NLOPB assigns all expenditures after first production to the production cost category which is problematic from an accounting perspective since expenditures for both short-term and long-lasting items (e.g., new wells) are mixed, and because of this mixing of cost categories, the estimated unit production cost will be higher compared to the standard use of the term.

Using the C-NLOPB categorization, inflationadjusted production cost averaged $\$ 23.4 / \mathrm{bbl}$ from 2006 to 2018 and varied from $\$ 16.8 / \mathrm{bbl}$ at Hibernia, to about $\$ 36 / \mathrm{bbl}$ at Terra Nova and White Rose/ North/Amethyst (Table 13; Fig. 33). Standard deviation of production cost during this time was $\$ 9.6 /$ bbl. Composite averages are smaller, from $\$ 15.8$ at Hibernia, \$27.0 at Terra Nova, and $\$ 34.2 / \mathrm{bbl}$ at White Rose/North/Amethyst. Production cost at Terra Nova and White Rose is more than twice as large as Hibernia reflecting the primary difference between GBS and FPSO developments. Differences in operations personnel, maintenance, and chemical needs to support subsea wells are greater than dry tree wells.

A better estimate of Newfoundland production cost requires that the capitalized items in production expenditures be estimated ${ }^{24}$ and excluded from the metric.

\footnotetext{
${ }^{24}$ Some useful data may be inferred from development drilling activity and reported expenditures, but caution is needed in interpretation. From 2006 to 2018, for example, there were five years where no development wells were drilled at Terra Nova, and eight years where a total of 12 wells were drilled. Using the zero-well years as a baseline and not performing any inflationadjustment, production cost for these years is computed as $\$ 15.4 /$ bbl. For drilling years, production cost is computed to be $\$ 29.6$ / bbl.
}

\section{Life Cycle Operating Cost and Development Well Cost Relationship}

To estimate operating cost according to its standard formulation (i.e., no capitalized expenditures), capitalized items in the production expenditure category must be estimated and excluded from the metric. Development wells are believed to be by far the largest and most important capitalized cost in C-NLOPB's production expenditure category, and thus the focus of the adjustment.

If production cost at each field was known, average development well cost could be estimated, and vice versa, if development cost was known, average production cost could be estimated using the average well cost relationship:

Production expenditure $(\$)$ - Operating cost $(\$ / \mathrm{bbl}) *$ Production $(\mathrm{bbl})$ Number of development wells

In Table 14, a theoretical relationship between life cycle operating cost and average well cost using this relation is depicted. Enter the column at the left at the assumed average production cost and read off the row entry for the average development well cost for the field. For example, at Hibernia, if average life cycle production cost is $\$ 8 / \mathrm{bbl}$, then average development cost is estimated at $\$ 64$ million/well. Similarly, if average production cost was $\$ 18 / \mathrm{bbl}$ at Terra Nova, then average development well cost would be $\$ 119$ million. The different sensitivities at the three fields are the result of different field characteristics. If one enters the tableau from the right at the assumed average development well cost, life cycle production cost can be estimated continuing leftward. For example, if average development well cost at Terra Nova is $\$ 70$ million (Table 2), then average production cost would be estimated at about $\$ 21 /$ bbl. 
Table 13. Average inflation adjusted production cost statistics offshore Newfoundland, 2006-2018. Source: Data from C-NLOPB

\begin{tabular}{lcccr}
\hline Production cost & Hibernia & Terra Nova & White Rose/North Amethyst & Total \\
\hline Composite average $(\$ / \mathrm{bbl})$ & 15.8 & 27.0 & 34.2 & 21.6 \\
Annual average $(\$ / \mathrm{bbl})$ & 16.8 & 36.4 & $35.3(49.4)^{\mathrm{a}}$ & 23.4 \\
Standard deviation $(\$ / \mathrm{bbl})$ & 8.9 & 24.5 & $19.7(54.3)^{\mathrm{a}}$ & 9.6 \\
\hline
\end{tabular}

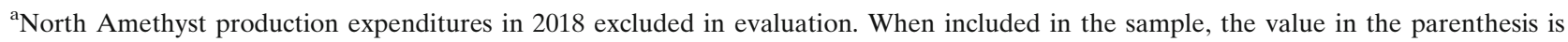
obtained

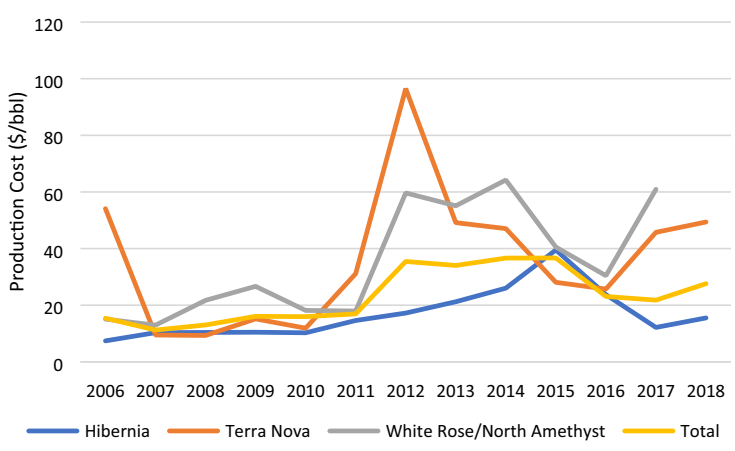

Figure 33. Production cost at Newfoundland's offshore developments include capital spending on development wells drilled after first production. White Rose/North Amethyst production cost in 2018 is not reported since the statistic falls significantly outside of the graph bounds. Source: C-NLOPB.

\section{Adjusted Production Cost}

At Hibernia and Hebron, assuming \$40 million per development well, development well expenditures of $\$ 6.2$ billion were allocated to production cost. At Terra Nova and White Rose/North Amethyst, assuming $\$ 60$ million per development well leads to $\$ 3.2$ billion allocated to production. In total, of the reported $\$ 25.8$ billion production expenditures from 1997, $\$ 9.4$ billion is estimated to arise from development drilling, leading to $\$ 16.4$ billion adjusted cost, or an adjusted cost of $\$ 8.5$ per barrel produced. If development wells cost on average twice as much as assumed, $\$ 18.8$ billion would arise from development drilling, and adjusted production cost would be $\$ 7$ billion, or about $\$ 3.7$ per barrel.

\section{CONCLUSIONS}

Offshore Newfoundland is characterized by severe storm and sea conditions, including the presence of icebergs, which challenge all aspects of exploration and development. Developments in extreme environments can be commercialized and performed in an environmentally responsible manner but require careful oversight by regulators, large investments by operators, and long development cycles to bring to fruition. Newfoundland waters are one of the most challenging offshore environments worldwide and require investors to take large economic risks in development, but Canada's transparent and stable political regime, rule of law, and favorable fiscal terms balance the equation and have encouraged investment in the region.

From 1966 to 2019, operators have spent a total of $\$ 84$ billion Canadian dollars in exploration, development, and production activities offshore Newfoundland and Labrador, approximately $\$ 15$ billion in exploration, $\$ 36$ billion in development, and $\$ 33$ billion in production. Four major projects have been developed offshore Newfoundland, and since production started in 1997, operators have produced about 2 billion barrels of an estimated 3.3 billion barrels recoverable oil.

From 1998 to 2018, exploration and delineation drilling averaged $\$ 90.9$ million per well, and development wells drilled from MODUs were nearly identical at $\$ 91.1$ million per well. Both exploration and development wells were drilled from MODUs, so perhaps the similarity in results are not that surprising. The average injector well cost slightly less at $\$ 68.8$ million per well. On a per meter basis, exploration and delineation drilling cost $\$ 26,500$ per meter compared to $\$ 15,900$ to $\$ 24,000$ per meter for development wells.

On a regional basis, development expenditures normalized by cumulative production was $\$ 32.5 / \mathrm{bbl}$ since the start of production and is expected to fall to $\$ 22 / \mathrm{bbl}$ when recoverable reserves have been extracted. Average inflation-adjusted production cost from 2006 to 2018 was estimated at $\$ 23.4 / \mathrm{bbl}$ and ranged from $\$ 16.8 / \mathrm{bbl}$ at Hibernia to about $\$ 35$ / bbl at Terra Nova and White Rose. 
Table 14. Theoretical relationship between life cycle operating cost and development well cost offshore Newfoundland

\begin{tabular}{lccc}
\hline Operating cost $(\$ / \mathrm{bbl})$ & \multicolumn{2}{c}{ Development well cost (\$million) } \\
\cline { 2 - 4 } & Hibernia & Terra Nova & White Rose/North Amethyst \\
\hline 4 & 107 & 411 & 218 \\
6 & 86 & 370 & 202 \\
8 & 64 & 328 & 185 \\
10 & 43 & 286 & 168 \\
12 & 22 & 244 & 152 \\
14 & & 203 & 135 \\
16 & & 160 & 119 \\
18 & & 119 & 102 \\
20 & & 77 & 86 \\
22 & & 55 & 69 \\
24 & & 53 \\
26 & & & 36 \\
28 & & & 19 \\
30 & & & \\
\hline
\end{tabular}

\section{APPENDIX A: ICEBERG ALLEY AND MANAGEMENT STRATEGIES OFFSHORE NEWFOUNDLAND}

An iceberg is a body of floating ice that has broken away from a glacier and thus distinct from sea ice which is formed in the ocean. When water freezes, the molecules form hexagonal structures which form stacks of crystals with a lot of empty space, allowing ice to float (Olovsson 2018). When sea ice forms, most of its salt content is ejected, and so sea ice is mostly freshwater. Multi-year sea ice is usually less saline than first year sea ice and is usually suitable to melt and drink.

Water has a very unusual property in its solid state. The density of distilled water at $20{ }^{\circ} \mathrm{C}$ is $0.9982 \mathrm{~g} / \mathrm{cm}^{3}$. As water cools down, the density increases and reaches a peak at $4{ }^{\circ} \mathrm{C}$, but then upon further cooling, the density declines again until it freezes at $0{ }^{\circ} \mathrm{C}$. Ice has a density of $0.915 \mathrm{~g} / \mathrm{cm}^{3}$, significantly less dense than water whereas for almost all other substances their solid form is denser and thus sinks in their liquid state.

Seawater is slightly more dense than freshwater because of the dissolved salts it contains. The salinity of seawater is typically 35 parts per thousand ppt (3.5 wt\%) by mass, and at $20^{\circ} \mathrm{C}$ its density is $1.0248 \mathrm{~g} / \mathrm{cm}^{3}$. At $40 \mathrm{ppt}$ and $20^{\circ} \mathrm{C}$, the density is $1.0286 \mathrm{~g} / \mathrm{cm}^{3}$. Seawater freezes at a temperature depending on salinity level but usually starts around $-1.8^{\circ} \mathrm{C}$. Since most salt is ejected during freezing, it has a density like freshwater, $0.915 \mathrm{~g} / \mathrm{cm}^{3}$, and floats on top of seawater.
Icebergs are calved off as glaciers discharge into the sea, and as they melt, they assume dramatic shapes with pinnacles and saddles formed by melting and wind action. Most calving occurs during the summer months when temperatures are highest, and icebergs usually take between one and three years to reach Newfoundland waters in an area known as Iceberg Alley. About 10,000 or so icebergs are calved off glaciers in the Arctic each year, most along the western coast of Greenland, but these levels are expected to increase with climate change (Truillo and Thurman 2014). Ocean currents driven by strong winds carry the icebergs south along the east coast of Newfoundland and as far south as Philadelphia, Pennsylvania $\left(40^{\circ} \mathrm{N}\right)$. Once detected, icebergs are monitored and managed before they pose a threat to operations in the region.

About $85 \%$ of icebergs crossing the Grand Banks originate from the tidewater glaciers of West Greenland, with the remainder calving from East Greenland glaciers, Baffin Bay and Ellesmere Islands. About $90 \%$ of the mass of an iceberg ${ }^{25}$ lies

\footnotetext{
${ }^{25}$ This is seen as follows. For an iceberg floating in water, the pressure below the iceberg must be equal to the pressure in the water column at the same horizontal level to be in equilibrium (Afanasyev 2018). If $h_{i}$ is the total height of the iceberg, $\rho_{i}$ the density of ice, $\rho_{w}$ the density of seawater, and $h$ the depth below the waterline, then equating pressures $\rho_{i} g h_{i}=\rho_{w} g h$ leads to the depth of the iceberg: $h=\rho_{i} h_{i} / \rho_{w}$. The density of ice is $0.915 \mathrm{~g} / \mathrm{cm}^{3}$, while the density of seawater depends upon salinity, pressure, and temperature conditions. Recall that more salt results in denser sea water and warmer temperatures make water less dense because of expansion. In high latitude surface waters during summer, $\rho_{w}$ ranges from 1.026 to $1.028 \mathrm{~g} / \mathrm{cm}^{3}$, leading to the conclusion that about $90 \%$ of the iceberg is submerged.
} 
below water and, in shallow water depth $(<100 \mathrm{~m})$, has the potential of contacting the seabed and poses an impact risk to subsea facilities (Fig. 34). Icebergs with a draft less than water depth are a collision hazard to surface structures, vessels, mooring lines, and production risers. In deepwater areas, iceberg scour of the seabed is not a concern because the water depth will greatly exceed the deepest draft iceberg.

The number and size of icebergs vary widely from year to year. Sizes range from tens of tonnes to several million tonnes, and the mean number of icebergs that enter a $1^{\circ}$ square $(\sim 60 \mathrm{~nm}$ per side $)$ near the platforms on the Grand Banks ranges from 40 to 400 per year. Without active management, this translates into about one iceberg impact per structure every 10 years! The paths of icebergs are usually very erratic driven by a combination of wind, current, and wave drift force, and so even if an iceberg appears to sail by it may circle back and create an impact threat. The drift speed of icebergs usually ranges from 0.3 to $1 \mathrm{~m} / \mathrm{s}$.

On Nansen's famous North Polar Expedition ${ }^{26}$ of 1893-1896, a curious observation on the movement of icebergs relative to wind direction led to a fundamental discovery by his crew mate and student W. Ekman, which later became known as Ekman transport.

Nansen noticed that icebergs drifted in a direction at an angle to the direction the wind was blowing. Ekman considered the problem in his thesis and found that the average movement of the whole water column is actually perpendicular to the wind direction $\left(90^{\circ}\right.$ to the right-hand side in the northern hemisphere), and the direction taken by an iceberg depends on how deep the iceberg extends below the surface. Shallow keels will move in the general direction of the wind; deep keels will move at a greater angle to the wind.

Detection, classification, and tracking are the primary components of ice management systems (Randell et al. 2009). Once a threat has been identified, ${ }^{27}$ active physical management is executed.

\footnotetext{
${ }^{26}$ Nansen's mission was to drift across the North Pole in the vessel Fram frozen in ice (and moving with the ice), and although Nansen did not reach the North Pole, he did reach $82^{\circ} \mathrm{N}$ latitude after a long and perilous journey.

${ }^{27}$ Detection tools include ice patrols of the US Coast Guard and Canadian Ice Service, marine radar, airborne radar, satellitebased radar, shore-based surface wave radar, platform support vessels, and side-scan sonar.
}

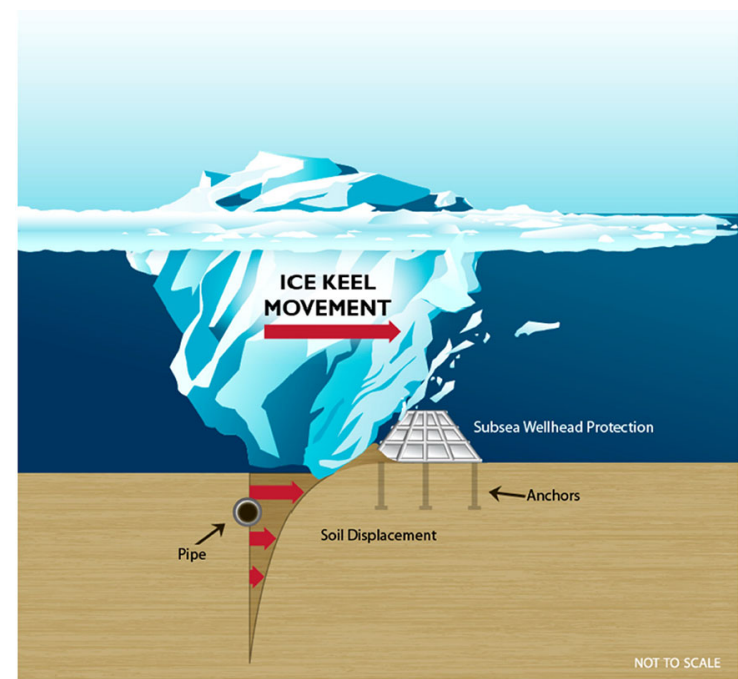

Figure 34. Subsea equipment needs to be buried to avoid ice keel. Source: C-CORE.

The two primary methods for deflection include towing and water cannon blasting. Towing is the most common practice with success rates reported as high as $85 \%$. On medium-size icebergs, defined as having a $60-120 \mathrm{~m}$ waterline length, towing uses a single towline or an iceberg net. For larger icebergs in higher seas, dual-vessel towing may be employed. For smaller icebergs (known as growlers or bergy bits) and shorter distances, vessels equipped with water cannons spray seawater at the base of the iceberg, which can break the iceberg or change its direction. Prop wash refers to when a vessel backs up close to an iceberg and the wash from the propellers creates a localized current, thrusting the berg along a different course.

Platform support vessels collect information on ocean current and move alongside the iceberg to measure its draft, shape, and mass (Fig. 35). Stability analysis is performed, since whenever icebergs center of gravity and buoyancy shift, they can roll over and create safety hazards for towing operations. Using mathematical modeling techniques, combined with wind and wave forecasts and other physical and environmental information, iceberg movements are predicted and those which may drift close to the production area are identified. Icebergs that are identified to require intervention are approached while they are $20 \mathrm{~km}$ or more away from the platform.

For facilities that are designed to disconnect and relocate to avoid interaction with icebergs (e.g., 
FPSOs and MODUs), management zones are defined (Fig. 36). Zone size is dynamic and determined by iceberg drift and T-time, the time required to suspend operations, secure the well, and shut in production. For operations to be safe, the T-time must be greater than the time for the iceberg to reach the facility. If the Alert Zone shrinks to the size of the Exclusion Zone, the facility is downmanned and wells secured. Iceberg towing is carried out in the control zone to prevent icebergs from breaching $^{28}$ the Alert Zone.

\section{APPENDIX B: DEPTH VS. TIME AND DEPTH VS. COST PLOTS}

Depth vs. time and depth vs. cost plots represent a graphical summary of the time and cost of the drilling and completion process through the progression of the measured depth of the well. Depth-time plots are often used for drilling the well, and completion operations may or may not be included in the plot. It is usually not obvious what time and cost categories are included without a review of accompanying documents (e.g., total well cost in drilling operations will only include drilling cost).

Before a well can be drilled, engineers design the well on paper and specify all the required parameters involved in the process, such as casing dimensions and type, and drilling mud regime, for every stage of the process to target depth (Mitchell and Miska 2011). An Authorization for Expenditure (AFE) is required before activities commence. The operator generates an expected (P50) depth-time plot, and a best-in-class plot may also be included.

The depth-time plot appears as a downward staircase as the well is drilled deeper and further away from its spud point. The measured depth is plotted along the y-axis with increasing values going down the axis. Measured depth represents the amount of borehole drilled along the wellbore. Flat

\footnotetext{
${ }^{28}$ On March 29, 2017, an iceberg entered the 0.25 nautical mile ice exclusion area of the SeaRose FPSO. There were 84 personnel and 340,000 barrels of crude oil onboard at the time. In accordance with Husky's Ice Management Plan filed with CNLOPB, the SeaRose FPSO should have disconnected and sailed away from the threatening iceberg. That action was not taken, and personnel were at one point instructed to muster and brace for impact. Ultimately, the iceberg did not contact the SeaRose FPSO or subsea infrastructure, and there were no injuries, no environmental damage, and no damage to the facilities.
}

portions of the plot arise when there is no new wellbore constructed, which will occur when tripping, ${ }^{29}$ installing and cementing casing, coring, weather delays, etc. The well-on-paper depth-time plot and AFE are based on the expected drilling requirements and well casing program, and the benches reflect the trips planned to change drill bits and related construction activities.

Operations are expected to follow the curve, but in practice wind up ahead or behind schedule. Unplanned events (e.g., weather, ice events, equipment failure) will cause deviation from the expected curve, and sometimes significantly. If the changes are significant, one or more supplemental plots and AFEs may be required, and these are often plotted on the original curve. Supplemental AFEs are usually required if the occurrence of an unplanned event increases cost by $10 \%$ or more of the planned cost.

When the target is reached, the depth-time and cost-time plots bottom out and stay flat since no new wellbore is being drilled, but both time and cost continue to increase and extend the lines along the $\mathrm{x}$-axis. Flat time along the bottom of the depth-time plot is usually longer than other steps down the stairs since during this time the well is getting ready to be handed over to completions or completions operations are included in the plot. Completion activities may occur immediately after the well has been drilled or the well may be suspended and completed later. Both are common and the type of well and rig schedule determine if separate or continuing operations are performed. Not all the bottom flat time is due to completion activities, but for many wells if completion activities are included in the plot, a significant portion of this bench will be due to completion activities.

When drilling out a section of a well, instability may occur and if cannot be brought under control, the section will be abandoned and plugged back, and a sidetrack will be drilled from higher up in the well, causing the depth-time and cost-time plots to depart from its downward progression and abruptly rise to the depth where the sidetrack kicks off before following the staircase pattern again. Any rise in the plots indicates bypasses or sidetracks which may be planned or unplanned. Exploration wells often have planned sidetracks to test different targets, but in

\footnotetext{
${ }^{29}$ Inserting and removing drill pipe from a well to replace a drill bit or malfunctioning equipment is referred to as tripping. Obviously, when drillers are tripping new hole is not being drilled.
} 


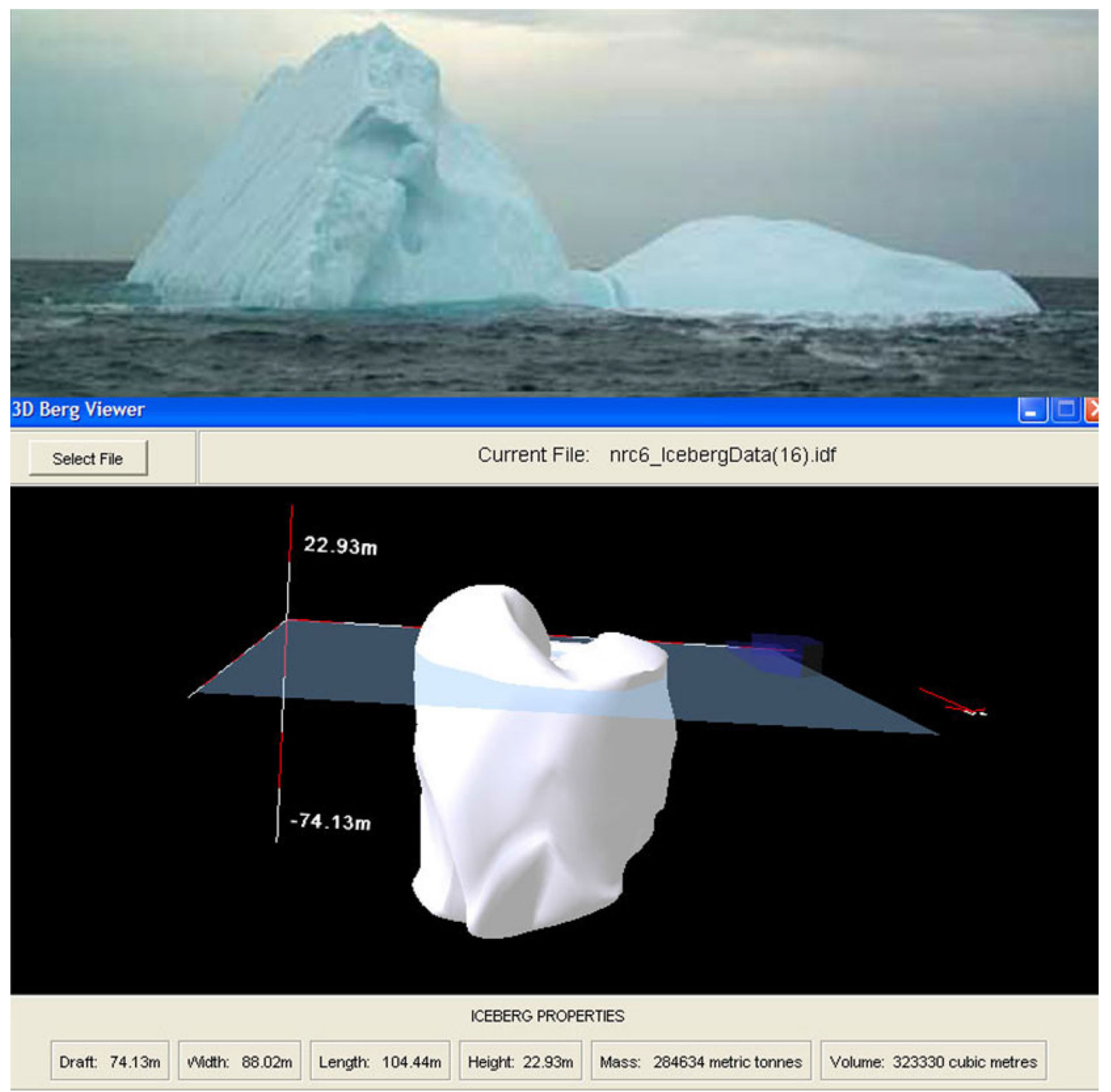

Figure 35. Iceberg profile and properties calculated from three-dimensional shape measurements. Source: Oceans Ltd.

development wells sidetracks are often performed because of problems in drilling or accessing a productive reservoir (e.g., the reservoir may be cemented and a new horizon has to be found).

Example White Rose E-18 7 Water Injector Well. The time vs. depth curve for Husky Oil's White Rose E-18 7 horizontal water injector well is depicted in Figure 37. The well was spud on December 10, 2006, reached total depth on February 12, 2007, and the
GSF Grand Banks was released on March 2, 2007. The well took about 84 days to drill and cost about $\$ 35.5$ million before the well was suspended and completed later (Fig. 38). Well completion was finished on May 8, 2007, at a cost of $\$ 11.9$ million.

Example Terra Nova L-98 9 Producer Well.

Petro-Canada's Terra Nova L-98 9 well was spud on March 4, 2004, reached total depth of $3740 \mathrm{~m}$ on April 8, and was completed on April 29 at a total 


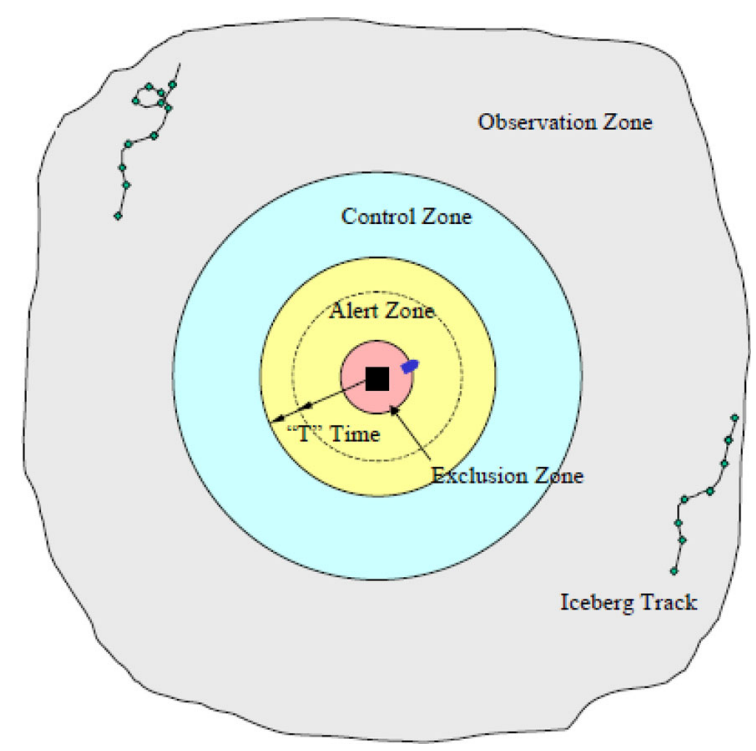

Figure 36. Schematic of ice management zones and T-time illustration. Source: C-NLOPB, C-CORE.

cost of $\$ 33.9$ million (Fig. 39). The AFE budget is shown in red with the actual drilling cost shown in blue. Completion cost was a small part of the well's total cost.

\section{APPENDIX C: OIL PRODUCTION FACILITY REQUIREMENTS}

The main function of an oil production facility is to stabilize the produced crude by separating the water and gas from the oil streams, the oil and water from the gas streams, and the oil and gas from the water streams, and then treating each output to satisfy transport and injection specifications, and offshore disposal requirements. For example, crude for shuttle transport is often required to meet the specifications for vapor pressure of $75.8 \mathrm{kPa}$ at $50 \mathrm{C}$ and $\mathrm{BS} \& \mathrm{~W}<0.5 \mathrm{vol} \%$.

\section{Produced Water}

Water that is produced with petroleum is referred to as produced water. Most offshore platforms dispose of produced water directly into the ocean but must meet stringent regulations on the entrained and dissolved oil and other chemicals in the produced water. In Arctic regions (Beaufort and
Barents Sea) and environmentally sensitive regions (e.g., Garden Banks in the US Gulf of Mexico), no discharge rules apply. The wide variation in the concentration and type of constituents sometimes make produced water challenging to treat and discharge.

The physical and chemical properties of produced water depend upon the location of the field, the geologic formation, and the type of hydrocarbon produced (Veil and Clark 2011). The major constituents of concern are salt content (expressed as salinity, conductivity, or total dissolved solids), oil and grease (organic compounds captured through an n-hexane extraction procedure), inorganic and organic compounds introduced as chemical additives to improve drilling and production operations, and naturally occurring radioactive material.

Changes in produced water due to pressure and temperature changes from production can impact precipitation of scales and corrosion which may lead to leaks and costly repairs if not inhibited and monitored. Inhibition of most scales is through application of organic compounds which act to poison (prevent) the growth sites of the crystals. Corrosion mitigation typically takes investment in corrosion-resistant alloys and/or a chemical corrosion-inhibition/monitoring program.

\section{Water Injection}

Water may be injected into oil reservoirs to supplement oil recovery, and in each of the producing fields offshore Newfoundland, water is injected into one or more formations. Water injection is commonly used in reservoirs with aquifer support to improve oil recovery and to maintain reservoir pressure to avoid compaction. Seawater will generally require treatment and the type of treatment and cost depends on the source and issues identified. If operators inject water into reservoirs to maintain pressure, they typically use seawater with some chemicals since this is the lowest cost option. In some cases, subsurface water may be processed if seawater causes injection problems. To inject produced water, ${ }^{30}$ suspended solids and oil must be

\footnotetext{
${ }^{30}$ There are also other risks involved. Souring potential is usually much greater than with injecting sea water, fracture containment may be compromised, and scaling potential is increased. A dedicated produced water disposal reservoir may not be available or in the size required for water volumes.
} 


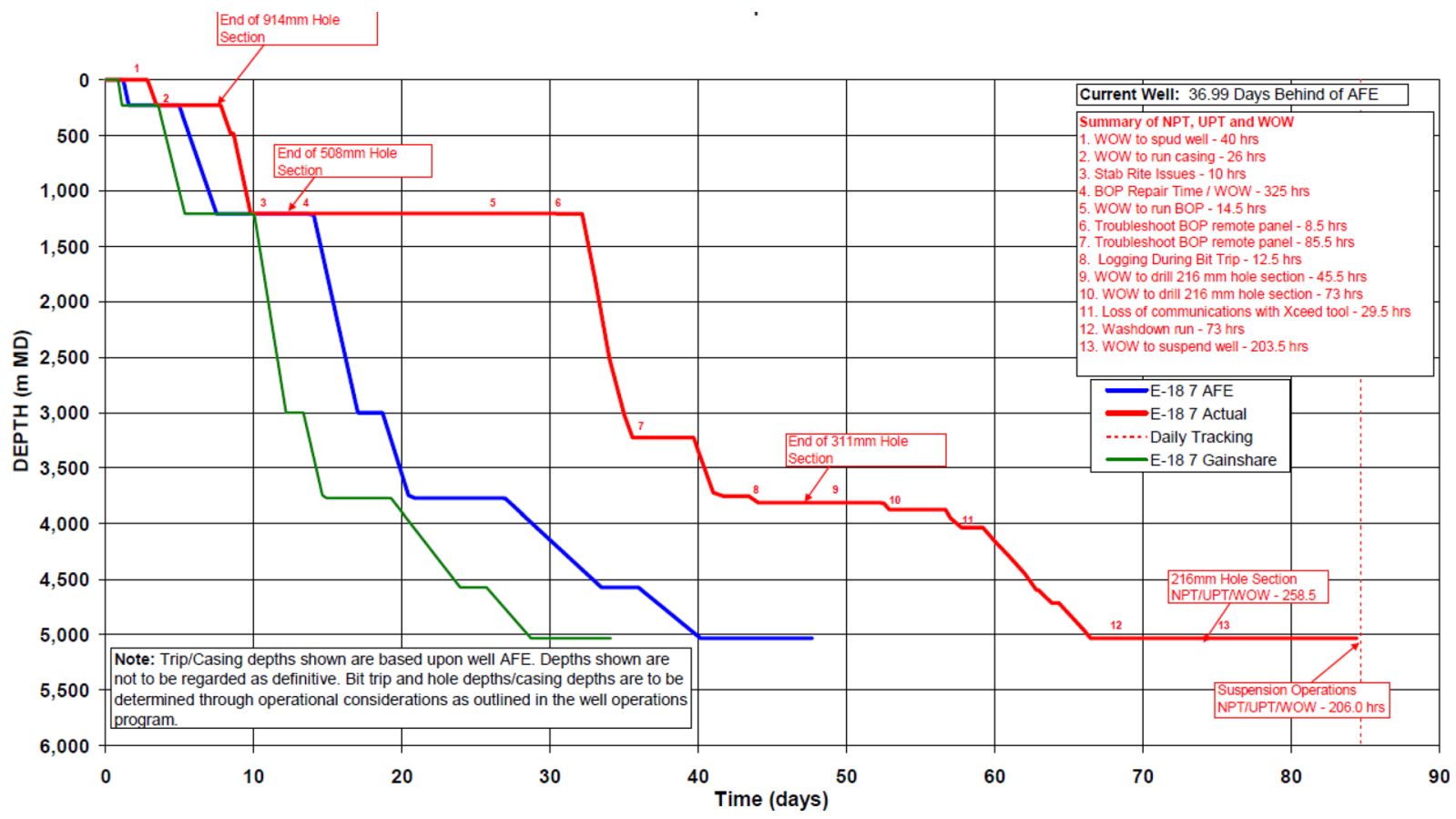

Figure 37. Water injector well E-18 7 in the White Rose Ben Nevis/Avalon formation (red curve) took 84 days before the well was suspended for completion. Source: Husky Oil.

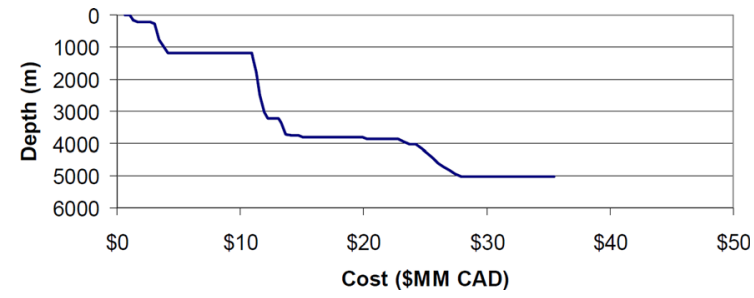

Figure 38. Water injector well E-18 7 in the White Rose Ben Nevis/Avalon formation cost about $\$ 35.5$ million before handed over to completions. Source: Husky Oil.

removed to an appropriate degree to avoid plugging and fouling the reservoir, and this is usually only pursued if produced water disposal is prohibited.

The operational requirements for seawater injection generally require filtration, deoxygenation, and corrosion control. The details of the treatment steps are specific to each project. For example, some projects may require injected water to be filtered to $1 \mu \mathrm{m}$, while other systems may require $10 \mu \mathrm{m}$. Deoxygenation in some systems may be achieved by chemical addition; other systems may require gas stripping and chemical treatment. Each process will have its own capital and operating cost requirement.

Seawater that has been filtered, deaerated, and treated to control oxygen levels and bacteria is me- tered and injected into one or more oil zones of specially drilled water injection wells. The volume of injected seawater is usually about the same quantity as the volume of crude and produced water extracted to match voidance replacement.

\section{Gas Injection}

Gas can be injected into reservoirs to supplement recovery by maintaining reservoir pressure or as a means of disposing of gas which cannot be flared or used. Surplus gas in each of the Grand Banks fields is compressed and reinjected back into reservoirs. Generally, there is no need to control hydrocarbon dew point as in export gas since injected gas after compression will get hotter not cooler, but it may be attractive to remove heavy hydrocarbons for economic reasons. Dehydration is required to avoid water dropout and corrosion problems. A topsides dehydration unit dries the produced gas to a water content of about $1 \mathrm{lb} / \mathrm{MMcf}$ to eliminate the potential for hydrate formation. In water injection regions, gas flood is balanced with water volumes for optimum pressure management. 


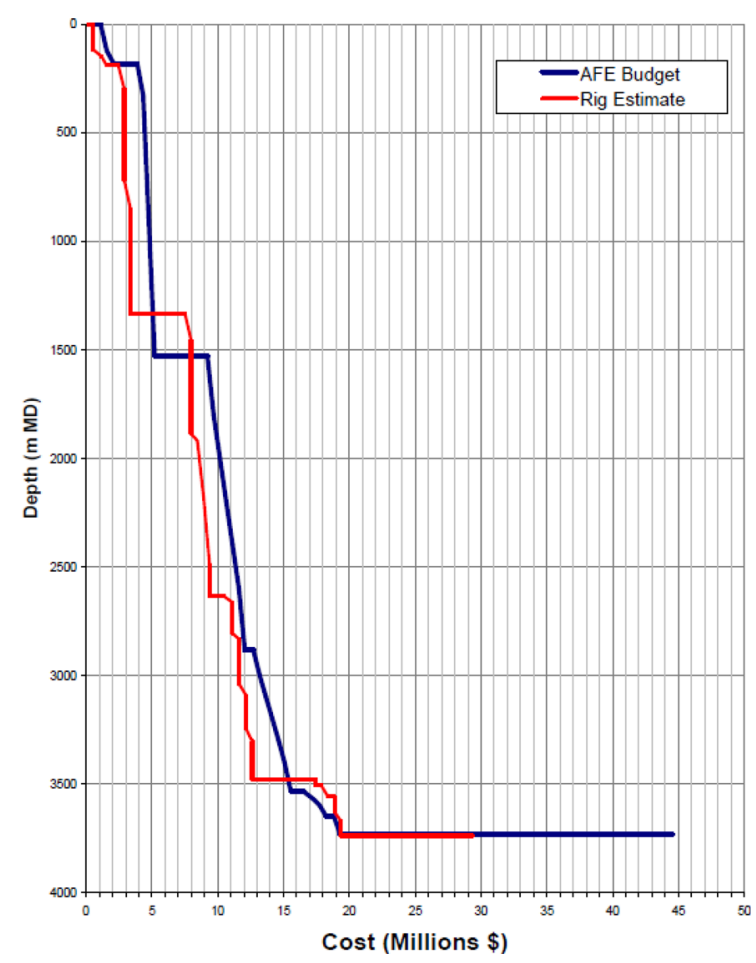

Figure 39. Drilling and budgeted cost for producer well L-98 9 in the Terra Nova development. Source: Petro-Canada.

Gas lift is a common method of artificial lift which uses high-pressured gas to lift well fluids. Natural gas injected in the production tubing within the wellbore reduces the density of fluids, which acts to lower the flowing bottom hole pressure, which increases flow from the reservoir to wellbore. Gas lift is easy to install, robust, and effective over a broad range of producing conditions and assumes the availability of a continuous supply of lift gas. All the producing fields offshore Newfoundland apply gas lift in operations, some more than others (recall Table 3). Gas injection into a reservoir requires a gas injection well, whereas gas lift transports gas from the topsides to the wellbore, through tubing where it helps lift the crude out of the hole, and after topsides separation is then recirculated in a closedloop system.

\section{REFERENCES}

Afanasyev, Y. D. (2018). Physical oceanography-a short course for beginners. Newfoundland: Smithville Crescent Publishing House.
Canadian Environmental Assessment Agency. (2020a). Decision statement issued under Section 54 of the Canadian Environmental Assessment Act, 2012 to Equinor Canada Ltd, for the Flemish Pass exploration drilling project. Retrieved November 11, 2020 from https://iaac-aeic.gc.ca/050/docume nts/p80129/129198E.pdf.

Canadian Environmental Assessment Agency. (2020b). Impact Assessment Agency of Canada. 2020. BHP Canada, Central Ridge and West Flemish Pass exploration drilling projects-public comments invited. Sep 30. Retrieved November 11, 2020 from https://www.canada.ca/en/impact-assessment-a gency/news/2020/09/bhp-canada-central-ridge-and-west-flemi sh-pass-exploration-drilling-projects-public-comments-invi ted.html.

Carrick, G. J., Delong, I., Ewida, A. A., \& Knight, R. J. (2005). East coast of Canada: An industry perspective on the opportunities and challenges. In: OTC 17575. Offshore Technology Conference, Houston, TX, May 2-5.

Cornaglia, V., \& McNeill, A. (2018). Geoscience overview of the Hebron field. In: OTC 29070. Offshore Technology Conference, Houston, TX, April 30-May 3.

Elsborg, C. C., Power, A. K., \& Schuberth, P. C. (2005). Hibernia record well breaks extended reach drilling and completion envelope. In: SPE/IADC 92347. SPE/IADC Drilling Conference and Exhibition. Amsterdam, The Netherlands, Feb 23-25.

Gallun, R. A., Wright, C. J., Nichols, L. M., \& Stevenson, J. W. (2001). Fundamentals of oil and gas accounting (4th ed.). Tulsa, OK: PennWell Books.

Haugen, E., Hydro, N., Costello, J., Wilcox, L., Albrechtsons, E., \& Kelly, I. (2007). Reservoir management challenges of the Terra Nova offshore field: Lessons learned after five years of production. In: SPE 109587. SPE Annual Technology Conference and Exhibition, Anaheim, CA, Nov 11-14.

Hjelde, E. (2004). Disposal of disused offshore concrete gravity platforms. In: SPE 86813. SPE International Conference on Health, Safety and Environment, Calgary, Alberta, Canada, March 29-31.

Hoff, G.C., Johnson, R.C., Luther, D.C., Woodhead, H.R., \& Abel, W. (1994). The Hibernia platform. Proceeding of the 14th International Offshore and Polar Engineering Conference, Osaka, Japan, Apr 10-15.

Howell, G. B., Duggal, A. S., \& Lever, G. V. (2001). The Terra Nova FPSO turret mooring system. In: OTC 13020. Offshore Technology Conference, Houston, TX, April 30-May 3.

Kaiser, M. J. (2019). Decommissioning forecasting and operating cost estimation. Watham, MA: Gulf Professional Publishing.

Kaiser, M. J. (2021). Offshore oil and gas records circa 2020. Ships and Offshore Structures. https://doi.org/10.1080/17445302.202 0.1827633 .

Kaiser, M. J., de Klerk, A., Gary, J. E., \& Handwerk, G. E. (2020). Petroleum refining: Technology, economics, markets (6th ed.). Boca Raton, FL: CRC Press.

Kaiser, M. J., \& Narra, S. (2019). An empirical evaluation of economic limits in the deepwater U.S. Gulf of Mexico. Journal of Natural Gas Science and Engineering, 63, 1-14.

Kaiser, M. J., \& Pulsipher, A. G. (2007). Generalized functional models for drilling cost estimation. SPE Journal of Drilling and Completion, 22(2), 67-73.

Kaiser, M. J., \& Snyder, B. (2013). Capital investment and operational decision making in the offshore contract drilling industry. The Engineering Economist, 58(1), 35-58.

Lawrence, J. J., Sahoo, H., Teletzke, G. F., Banfield, J., Long, J. M., \& Maccallum, N., et al. (2013). Optimization of gas utilization to improve recovery at Hibernia. In: SPE 165240. SPE Enhanced Oil Recovery Conference, Kuala Lumpur, Malaysia, July $2-4$.

Lever, G. V., Dunsmore, B., \& Kean, J. R. (2001). Terra Nova development: Challenges and lessons learned. In: OTC 
13025. Offshore Technology Conference, Houston, TX, April 30-May 3.

Mikkelsen, J. K., Norheim, T., \& Sagatun, S. I. (2005). The Troll story. In: OTC 17108. Offshore Technology Conference, Houston, TX, May 2-5.

Mitchell, R. F., \& Miska, S. Z. (2011). Fundamentals of drilling engineering. Richardson, TX: Society of Petroleum Engineers.

Norman, P., Lochte, G., \& Hurley, S. (2008). White Rose: Overview of current development and plans for future growth. In: Proceedings of the 18th International Offshore and Polar Engineering Conference. Vancouver, BC, Canada, July 6-11.

Offshore Magazine. (2019). Worldwide survey of floating production storage and offloading (FPSO) units. August 2019. Poster 136. Available at http://www.offshore-mag.com/resou rces/maps-posters.

Olovsson, I. (2018). Wonders of water. Singapore: World Scientific Publishing Co. Ltd.

Paila, P., Singh, R. P., \& Abid, K. (2019). Technologies and practices to push the extended reach drilling envelope within the existing constraints. In: SPE 197123. SPE Abu Dhabi International Petroleum Exhibition and Conference, Abu Dhabi, UAE, Nov 11-14.

Pardy, C., Akinniranye, G., Carter, M., Crane, G., Wishart, L., Krepp, T., \& Foster, B. (2013). White Rose project drilling and completion performance evolution: A case study. In: SPE/IADC 163456. SPE/IADC Drilling Conference and Exhibition, Amsterdam, The Netherlands, March 5-7.

Randell, C., Freeman R., Power, D., \& Stuckey, P. (2009). Technological advances to assess, manage and reduce ice risk in northern developments. In: OTC 20264. Offshore Technology Conference, Houston, TX, May 4-7.

Reid, D., Dekker, M., \& Nunez, D. (2013). Deepwater development: wet or dry tree? In: OTC 24517. Offshore Technology Conference, Rio de Janeiro, Brazil, Oct 29-31.

Smith, H.A. (1997). Hibernia: Pioneering a new frontier. In: OTC 8397. Offshore Technology Conference, Houston, TX, May 5-8.

Stephens, P., Sheorey, U., Isenor, R., \& Ewida, A. (2000). Terra Nova-The flow assurance challenge. In: OTC 11915. Offshore Technology Conference, Houston, TX, May 1-4.

Truillo, A. P., \& Thurman, H. V. (2014). Essentials of oceanography. Boston, MA: Pearson Education Inc.

Veil J. A., \& Clark, C. E. (2011). Produced water volume estimates and management practices. In: SPE 125999. SPE International Conference on Health, Safety and Environment, Rio de Janeiro, Brazil, April 12-14.

Widinato, W., Khalifa, J., Younan, A., Karlsson, T., Stuckey, P., \& Gjorven, A. (2013). Design of Hebron gravity based structure for iceberg impact. In: Proceeding of the 22nd International Offshore and Polar Engineering Conference. Anchorage, Alaska, June 30-July 5.

Wolfe, K. J., Parker, G. J., Sellars, S. L. (2018). Hebron offshore development project overview. In: OTC 28695. Offshore Technology Conference, Houston, TX, April 30-May 3.

Woodfine, M., Bolivar, N., Trend, S., \& Ottesen, S. (2011). Hibernia well overcomes challenges to further extend worldwide extended drilling reach (ERD) envelope. In: $S P E$ / $I A D C$ 140318. SPE/IADC International Drilling Conference and Exhibition, Amsterdam, Netherlands, March 1-2. 